\title{
Building Information Modeling as an Effective Process for the Sustainable Re-Shaping of the Built Environment
}

\author{
Cecilia Mazzoli *(D), Marco Iannantuono, Vieri Giannakopoulos, Anastasia Fotopoulou (D), Annarita Ferrante \\ and Simone Garagnani $(\mathbb{D}$
}

Citation: Mazzoli, C.; Iannantuono, M.; Giannakopoulos, V.; Fotopoulou, A.; Ferrante, A.; Garagnani, S. Building Information Modeling as an Effective Process for the Sustainable Re-Shaping of the Built Environment. Sustainability 2021, 13, 4658.

https://doi.org/10.3390/su13094658

Academic Editor: Jaejun Kim

Received: 20 March 2021

Accepted: 19 April 2021

Published: 22 April 2021

Publisher's Note: MDPI stays neutral with regard to jurisdictional claims in published maps and institutional affiliations.

Copyright: (c) 2021 by the authors. Licensee MDPI, Basel, Switzerland. This article is an open access article distributed under the terms and conditions of the Creative Commons Attribution (CC BY) license (https:/ / creativecommons.org/licenses/by/ $4.0 /)$.
DA-Department of Architecture, University of Bologna, 40136 Bologna, Italy; marco.iannantuono2@unibo.it (M.I.); vieri.giannakopoulo2@unibo.it (V.G.); anastasia.fotopoulo2@unibo.it (A.F.); annarita.ferrante@unibo.it (A.F.); simone.garagnani@unibo.it (S.G.)

* Correspondence: cecilia.mazzoli2@unibo.it

\begin{abstract}
This paper focuses on the definition of a method supported by digital processes for a sustainable and user-orientated re-design of the existing building stock. Based on the analysis of the methodological and procedural aspects of the computational approach to architectural design in relation to different performance conditions, the research addresses the adoption of Building Information Modeling (BIM), intended as a powerful method for coordinating the complexity of the multiple, interdisciplinary and conflicting aspects involved in the rehabilitation of buildings. In addition to the advantages in terms of control and management, the BIM process has proven its effectiveness in tackling the issue of sustainability, allowing all actors involved in the research to share information and pro-actively control various outcomes of a building's performance, such as energy and environmental quality. To show the opportunities and limitations of the digital management in information-based processes, the activities carried out in the framework of the European Horizon 2020 project "Pro-GET-onE-Proactive synergy of inteGrated Efficient Technologies on buildings' Envelopes" are reported. The research, based on a case study method, which is applied to a student residence in Athens, demonstrates that BIM possesses great potentialities for developing effective and efficient construction and renovation processes toward buildings with high quality standards.
\end{abstract}

Keywords: Building Information Modeling; Industry Foundation Classes; sustainable design; Energy Efficient Buildings; Integrated Project Delivery; interoperability

\section{Introduction}

Contemporary architectural design, which is mainly expressed by digital language, is no longer based on traditional spatial concepts but on the holistic precept of communication, integration and participation [1-3]. In fact, the adoption of advanced digital methodologies offers clear advantages to the entire construction sector; greater efficiency, attractiveness and innovation can nowadays be achieved through a methodology by which different goals are optimally calibrated through an integrated multi-benefit approach [1,3-7].

The optimized management of design and construction processes assisted by Building Information Modeling (BIM) technology should be intended, in its broadest sense, as a methodology, a structured process that allows the generation of a digital model of a complex information system. This plethora of information contained in the digital model refers to the various technological systems and components that are part of the building or infrastructure in its different moments of the life cycle, from the early design phase, to its construction, management and maintenance, until its eventual demolition [1,5-8]. The concept of the "Digital Model" is the basis of the Industry 4.0 revolution and it is, in fact, a highly regarded topic in the construction sector, falling within the more general objective of innovation aimed at optimizing its processes. The main reason is that a precise virtual model of a building is a tool that offers enormous potential and developments that were unimaginable just a few years ago [1-3,7]. 
Another key concept is that the project team collaborates using the best tools at their disposal to ensure that the project achieves the proposed objectives. Compromises, which are always part of the design and construction processes, can thus be best addressed using the effectiveness of collaborative processes [1-3,7]. Ideally, an effective collaborative exchange between owners, designers, and main contractors (or sub-contractors) can ensure a maximum qualitative and economic advantage to the extent that they are able to exploit the digitalization of the process $[1,3,8,9]$.

However, practices based on 2D documentation, which are traditionally used in the sector and rely on floor plans, sections, elevations, views, technical reports, e-mails and so on, do not favor collaborative work. The need to overcome this drawback has been one of the main factors behind the rapid technological growth and procedural evolution we have witnessed in recent decades and which has seen the birth of current BIM-based methodologies $[1-3,8,10]$. These methods are in line with the European (EU) goal of taking urgent actions to combat climate change and its impacts by making cities and human settlements resilient and sustainable, promoting sustainable economic growth and ensuring sustainable consumption and fast production processes [11].

\section{Literature Review}

\subsection{State of the Art at EU Level}

The Architecture, Engineering and Construction (AEC) industry plays a key role in the modern society, economy and environment. Nevertheless, in order to enjoy an inclusive and sustainable growth in developed countries, a modern and efficient infrastructure is essential $[2,12]$. The focus is, therefore, tackling endemic inefficiencies and at the same time, improving the quality of designs, contributing to a healthier indoor environment, increasing its sustainability and reducing its cost.

Similar to other sectors, the AEC industry is now facing its own "digital revolution" and BIM is being adopted ever more as a strategic tool $[1,2,4]$. This appears to be even more crucial, as the sector represents roughly $9 \%$ of EU GDP and employs millions of people [4].

Governments across Europe are recognizing more and more the value of BIM and many professionals are taking proactive steps to encourage its use to secure economic, environmental and social benefits $[13,14]$. Reports mention that a wider adoption of BIM technologies could lead to up to $15-25 \%$ of savings to the global infrastructure market by 2025 [15] but the uptake and "maturity" of BIM can vary considerably from country to country, and from company to company-usually in relation to their size and position in the value chain.

The introduction of BIM in the design practice of Italian AEC professionals has been slow but has shown progress. Unfortunately, the number of professionals who have adopted BIM as their preferred procedure in their daily work is still low: this was one of the reasons why the Department of Architecture of the University of Bologna started to investigate the potential offered by the exploitation of this method in their research activities (i.e., EU $\mathrm{H} 2020$ projects).

The difference in adoption rates of BIM within Europe is considerable and it may be difficult to change established processes in the construction field. Furthermore, the construction industry, like many other manufacturing industries, is regulated by different standards, guidelines, codes of practice and national regulations that would need to be updated $[1,16]$.

Therefore, it is evident that there is a need and a defined opportunity window for a common EU strategic approach for the introduction of BIM. In this perspective, government policy and public procurement methods must be considered powerful tools to support this step-change in the sector [4]. Governments and public sector organizations are working to provide top-down leadership to encourage the sector toward the opportunity of digitalization. In this framework, collaboration between universities, industries, and private subjects at EU and national levels is essential to achieve this digital transformation. Companies themselves should seize the initiative and lead the industry transformation, 
as it appears clear that enormous opportunities are available through the application of new processes, technologies, materials and tools. Similarly, the University of Bologna is investing resources to participate in defining a successful model for the adoption of these technologies. The research conducted in the last three years, and which is still ongoing, will be presented in the following sections.

\subsection{EU Common Strategic Framework for the Implementation of BIM}

Digitalization - intended as the development and adoption of digital technologies and processes-is the main factor for the required transformation of the construction industry [4]. High-integrity data is the key, and the introduction of BIM represents the enabler and facilitator. This step, therefore, represents a unique opportunity to tackle common inefficiencies by taking advantage of digital workflows and technologies to shift to a higher level of performance.

In general, it is considered that to fully exploit the opportunity offered by digitalization, an approach based on universal principles, non-proprietary practices and open standards should be pursued. Additionally, three major challenges need to be addressed:

- Growing digital capacity across a diverse range of stakeholders;

- Defining consistent ways of working while maximizing competition and innovation;

- Communicating and engaging the shared value to clients and the supply chain in order to change behaviors [4].

The EU is therefore moving toward a common strategic framework for the implementation of BIM processes in order to tackle these challenges. Several recent EU-funded projects have focused on the integration of BIM solutions for the development of deep retrofit processes within the EU building stock [17-21]. Benefits of a common approach are, in fact, many: through collaborative work and the sharing of best practices, nations can boost their own BIM initiatives through the reuse of existing developments and knowledge. In addition, adopting a similar approach to neighboring countries for the encouragement of BIM will increase the strength and effectiveness of each individual national program. The alignment of an EU approach will encourage trade and growth opportunities across borders [4]. On the contrary, the creation of country-specific approaches would likely confuse the construction sector, discourage cross-border working and add a cost burden to the industry.

During the last decade, the European Union introduced many regulations to foster digitalization as a driver of productivity growth across industries and services, especially in the construction sector, which is characterized by a high presence of small and medium enterprises (SMEs), low capitalization, a low rate of higher educated employees, low investment in innovation, and a long supply chain.

Many of those common laws, whose mandatory elements were later adopted in each country by the introduction of local regulations, were supported by guidelines and best practices. For the research conducted by the University of Bologna, the Italian Ministerial Decree 560/2017, which describes the criteria for having BIM as a compulsory method in public procurement, has given a decisive boost to the use of digital 3D design tools based on parametric criteria. Additionally, in 2018 the ISO 19650-1:2018 [22] “Organization and digitization of information about buildings and civil engineering works, including building information modelling (BIM)-Information management using building information modelling" parts 1 and 2 were released. This common standard is still in development and other parts are expected to be published. However, this represents the current main reference to ensure open competition in the supply chain and the open sharing of information through software platforms.

The implementation of standards is advisable for many different reasons and harmonization of technical specifications can make industries much more efficient. Standards in software systems, interfaces and communication protocols will greatly facilitate the digitalization of the industry as a whole; standards in legal arrangements, such as alliances 
and Integrated Project Delivery (IPD) contracts, will reduce initial costs and anticipate legal complications for individual companies [12].

In general, common standards and classifications are needed in order to ensure that everyone speaks the same language; similarly, neutral formats, e.g. Industry Foundation Classes (IFC), are necessary for data models to enable systems and stakeholders to exchange information clearly [23-25]. Information acquired from in situ measurements, Information and Communications Technology (ICT) platforms and 3D documentation, such as mapping and laser scanning of the building, can be gathered in a BIM model in order to validate the enhanced performance of building components and systems and support any other related renovation measures. BIM models can serve as a basis for many decision-making processes during the whole renovation process and integrated design [26].

A uniform process for the delivery of information and a common working methodology is needed, but the international standardization of BIM remains a complex process involving many organizations [16].

\section{Integrated Approach as a Basis for a Sustainable Design Process}

Compared to many other sectors, the construction industry has not had such fast growth in technological development $[1,3,7,12]$. Nowadays, despite ground-breaking technological innovations, the construction industry remains fragmented and relies on traditional ways of collaboration among professionals, such as printed technical 2D drafting for shop drawings. For example, the data shows that more than $16 \%$ of AEC companies in the United Kingdom have never used BIM tools, while in Austria, the figure is as high as $49 \%$ [12]. This is believed to deeply penalize efficiency and productivity, having a huge impact also in terms of sustainability [1-3,7].

\subsection{Procedural Inefficiencies of Traditional Approach}

During the design phase, time and considerable use of resources are required to generate critical information for a project. In particular, analyses and simulations-which include cost estimations, energy and lighting analyses, clash detection, visualization and many more-are usually performed last, when it is very costly and time consuming to make substantial changes to the project. Additionally, because these iterative processes do not occur early in the design, inconsistencies are addressed late and often result in substantial trade-offs from the original design [1-3,9,27].

Drawings (plans, elevations, 3D visualizations) need to be continuously coordinated and updated to reflect all changes as they are implemented [1-3,7]. In addition, inconsistency, inaccuracy, and uncertainty in design, and especially in the re-design of existing buildings, make it very difficult to prefabricate materials off-site. As a result, fabrication and construction continue to take place on-site and only after the exact conditions have been established, resulting in more expensive, time-consuming and error-prone work $[1,12]$. This condition limits the use of prefabricated elements and affects the ability to predict and solve problems in advance.

Furthermore, the rehabilitation of existing buildings requires a particular multidisciplinary approach, which is due to the complexity of the multiple, interdisciplinary and often conflicting aspects involved in the rehabilitation of the existing building and its various performance aspects: structural, thermal, acoustic, plant engineering, etc. [28,29].

The feasibility of the initial project phase is perhaps the most important when it comes to analyzing the existing building, in terms of climatic data and defining appropriate bioclimatic design strategies, while implementing and optimizing façade and plant construction solutions [30].

For this purpose, the use of advanced calculation software is essential, integrating these aspects and enabling simulations to come as close as possible to reality.

Moreover, it is necessary to implement collaborative, multi-disciplinary and multiuser processes, which allow the projects to be developed, following an open, coordinated and coherent workflow amongst the various designers or collaborators that take part in the 
project. This could not be realized without the open standards and frameworks dedicated to interoperability and a non-proprietary data format for information sharing [31].

\subsection{Open Standards for Interoperability}

An essential aspect of a BIM-based methodology is the level of interoperability that it offers. The AEC industry is, by its nature, interconnected, thus it requires tools and processes that allow a smooth exchange of data between different professionals and between different applications on the market [32].

Interoperability can be defined as the workflow that allows interconnected applications to be executed by different users, using communication networks (LAN or WAN), through different types of computer systems, operating systems or software suites. In this way, BIM becomes a collaborative strategy in architecture and engineering, where the term "information" implies a sense of transparency among the project operators, aimed at generating a culture of teamwork based on efficiency and integration [33-35].

The proposed research method is based on the IPD methodology, which allows several members of a team to work on the same project at the same time, without causing interference between users [36-40].

One of the bases of this system is the division into sub-projects which are virtual entities that function as boxes for the elements belonging to the different parts of the building, such as architectural, structural or mechanical, electrical and plumbing (MEP) elements. The sub-projects offer the possibility for the different modeling actors to work on a local model that is bidirectionally connected to the other models shared on the network and that is constantly updated through the information sharing of the BIM project.

A rigorous examination of the various elements of the building, even at an early stage, may seem costly in terms of money and time, but it allows for the optimization of a prospective rehabilitation project. According to this assumption, both thermo-hygrometric comfort conditions and energy savings are primary characteristics to guarantee sustainable costs and improvement of the indoor environment [41-43].

As a result, Integrated Façade Systems (IFSs) should be considered a key aspect that relates to the active part of the building, which, over time, has solidified the increasing importance of the construction of sustainable buildings [29,42]. Therefore, those responsible for a project must consider, in addition to thermal insulation, the efficiency of systems and installations, fuel consumption, ventilation, lighting, and the quality and durability of materials throughout the life cycle of the building.

Thanks to the use of interchange formats, the specific applications used to solve the various features of a project do not have to be linked to a single software producer. For example, IFC is an open-source standard for the exchange of data models used in the design and construction of buildings between different software. It is intended for the exchange of information within a project team and between several software applications in the different phases of the project [44].

The current definitions of IFC models were developed by building SMART (International Alliance for Interoperability, IAI), an international association whose aim is to promote the efficiency of the AEC sector using open BIM standards [31].

The proposed design integration is rooted in a BIM model created in a specific software environment, whose contents are not just geometric shapes, and uploaded to the cloud with a Common Data Environment (CDE), then exported in IFC file format to share data structures with other tools and the different technical designers. Once the exchange with the BIM model has been created with the specific applications, changes can be made to this model, adding new information. In this way, the BIM project, as it takes on this information, is progressively enriched and completed.

Therefore, as the project develops, the information corresponding to the BIM model is updated from the IFC files generated by the specific applications. This is what is known as the consolidation of the BIM project (Figure 1). 


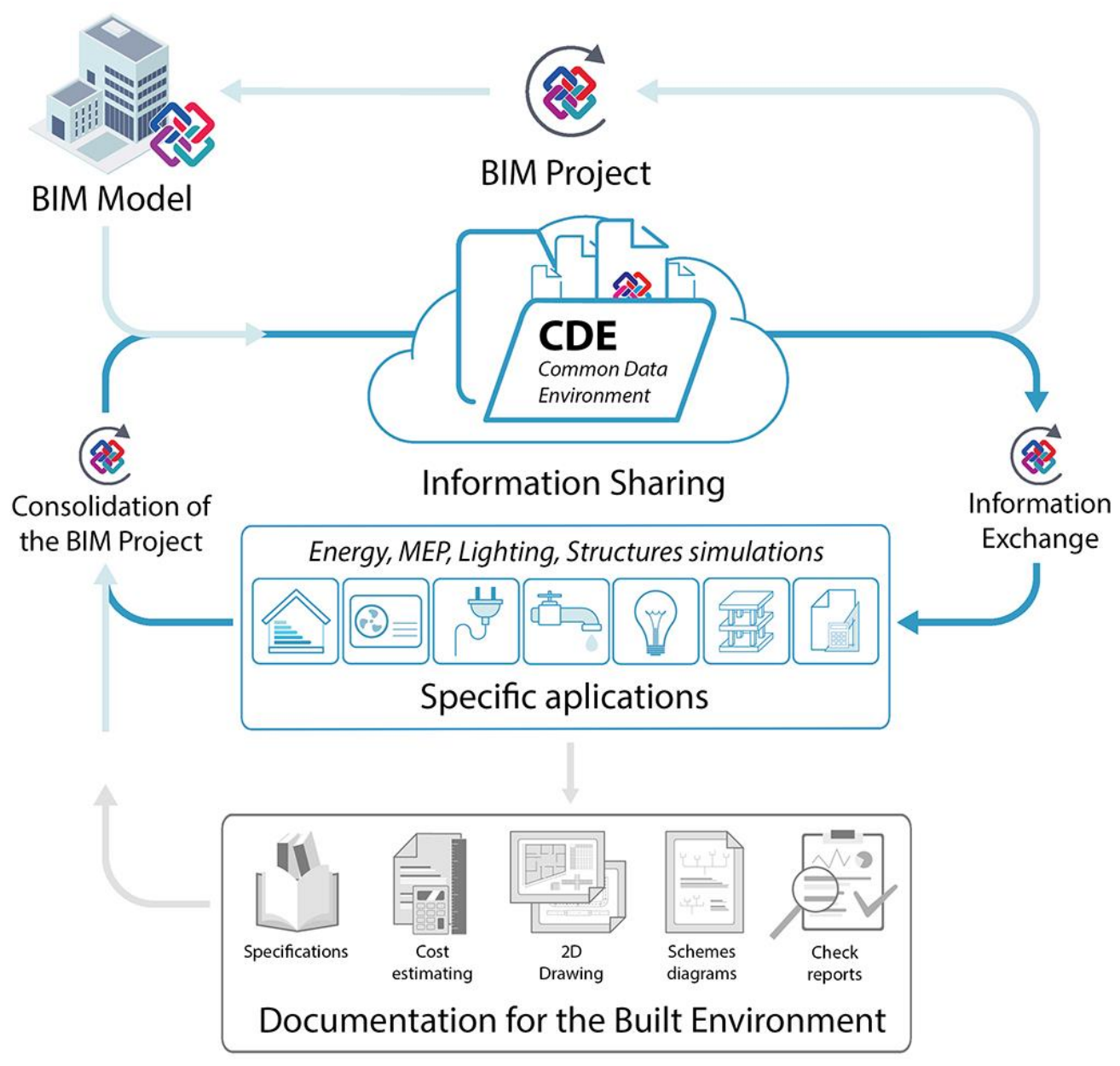

Figure 1. BIM workflow ( 2021, M. Iannantuono).

For the case study, which will be analyzed in the following section, specific applications were used for the calculation of thermal loads, dynamic energy modeling and simulation, and artificial and natural lighting of the building, which will be discussed in the following chapters.

\section{Practical Application of the Methodology to a Case Study}

4.1. Case Study Methodology

The objective of this paper concerns the presentation of a method of analysis and design for interventions oriented toward the rehabilitation of the existing heritage, according to an integrated and sustainable approach. This method was validated by applying it to a specific case study and it was possible to highlight the criticalities found while demonstrating its potentials.

The outcomes of an actual research project were useful to test data exchange methodologies in terms of an interdisciplinary approach. This project was developed by considering many perspectives, as introduced in the previous sections of this paper: the interdisciplinary process, interoperability issues among different software tools, and traditional resistance in adopting new approaches.

The research is based on a case study methodology with the aim to show the implementation of the proposed integrated approach for the deep renovation of a specific building, hence to validate the procedure. In particular, the analyses have been conducted within the framework of a Horizon 2020 project called "Pro-GET-onE-Proactive synergy of inteGrated Efficient Technologies on buildings' Envelopes" under grant agreement No. 723747 [45]. 
Pro-GET-onE solutions are proposed for four case studies located, respectively, in Greece, Italy, Romania and the Netherlands. The project covers the development of feasibility studies for the cases in Greece, Italy and Romania, while for the Athens case, a full scale prototype intervention for demonstration and validation purposes will be implemented [28,29].

This large-scale intervention model is meant to provide a significant impact on the building energy consumption and building safety. Furthermore, the primary goal to solve construction and safety problems in the context of near Zero Energy Buildings (nZEB) retrofitting is combined with a human-oriented approach which focuses on the priorities and expectations of the end users [3,7]. Therefore, the building design principle aspires to combine, with a single intervention, the highest performance in terms of:

- Energy efficiency - by adding new building envelopes and HVAC systems (heating, ventilation, and air conditioning) with prefabricated, plug-and-play, energy-efficient solutions that meet modern requirements;

- Safety - using adequate external metal structures to increase the overall structural capacity of the building, while supporting the new "skin" and adapting the structure to modern safety standards;

- Social sustainability-increasing the real estate value of buildings and the attractiveness of retrofit options, providing tailor-made and customized solutions for users, building owners and managers, minimizing the duration of the intervention and, therefore, the disruption to inhabitants.

These objectives are achieved through the application of modular solutions as well as an optimized management of the design, construction and site set-up processes assisted by BIM technology [3,7]. In fact, the strategy promotes the extension of an existing building with a seismic-resistant steel structure (exoskeleton) with the addition of extra spaces at each floor. Energy efficiency, seismic improvement and spatial extension are, therefore, provided by this strategy, which has been named as the GET system as a whole [46-48]. In this system, the end-user can choose and select the best option between different solutions, such as balconies, extra rooms and sunspaces according to the cost, energy performance and architectural value (Figure 2) [3,7].

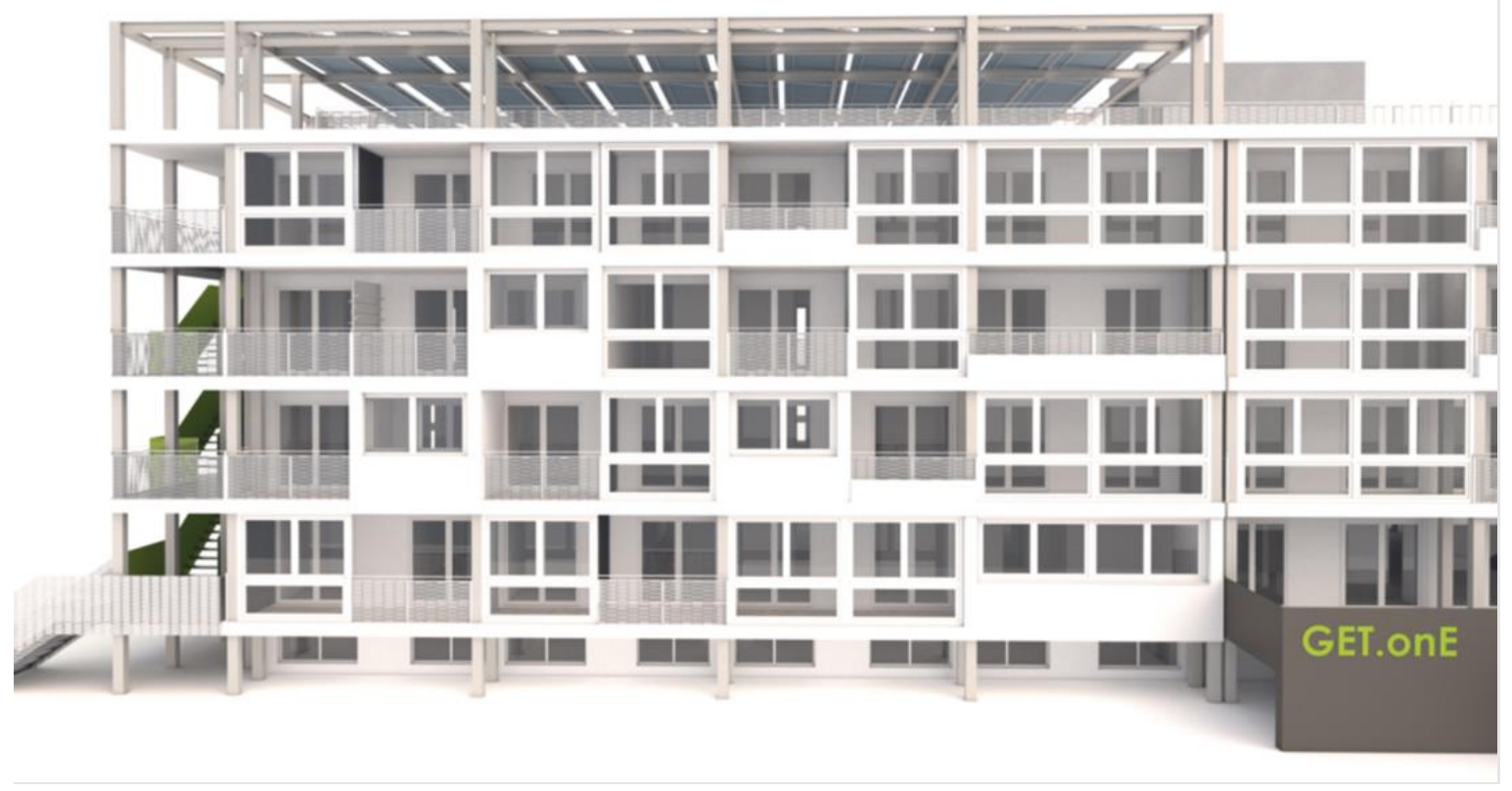

Figure 2. Early design of the GET façade (Athens Case). (ㄷ 2018, A. Cinti). 
One of the main objectives of the research project is to clarify the operating methods of such a complex process from the point of view of the different figures involved in the project, with particular focus on the use of BIM tools [3,7]. The design processes and their integration with the other production processes must, in fact, guarantee the quality of the results, i.e., the conformity of the product/service to the set objectives and the validity of the technological solutions adopted, particularly in relation to reliability (capacity to maintain performance over time), production costs and environmental sustainability [49].

The case study is an existing building located in the central-eastern part of the city of Athens, Greece, at the university campus of the Zografou area. It is a student residence of the University of Athens. The load-bearing structure is a reinforced concrete (RC) frame with semi-rigid RC floors and is designed to bear only vertical loads. This is a typology (pillars and beams, RC frame) of construction which is very common and can be seen throughout Europe. The existing windows are of single glazing with poor energy performance and the building envelope is devoid of thermal insulation, with the result that the building cannot be considered compatible with the actual requirements of energy and structural performance.

The building in question, named "B Building FEPA", is composed of 4 floors (including the ground level) and a basement (Figure 3). It has a rectangular shape, hosting 138 single rooms of about $9.50 \mathrm{~m}^{2}$. The gross building area is around $3642 \mathrm{~m}^{2}$.

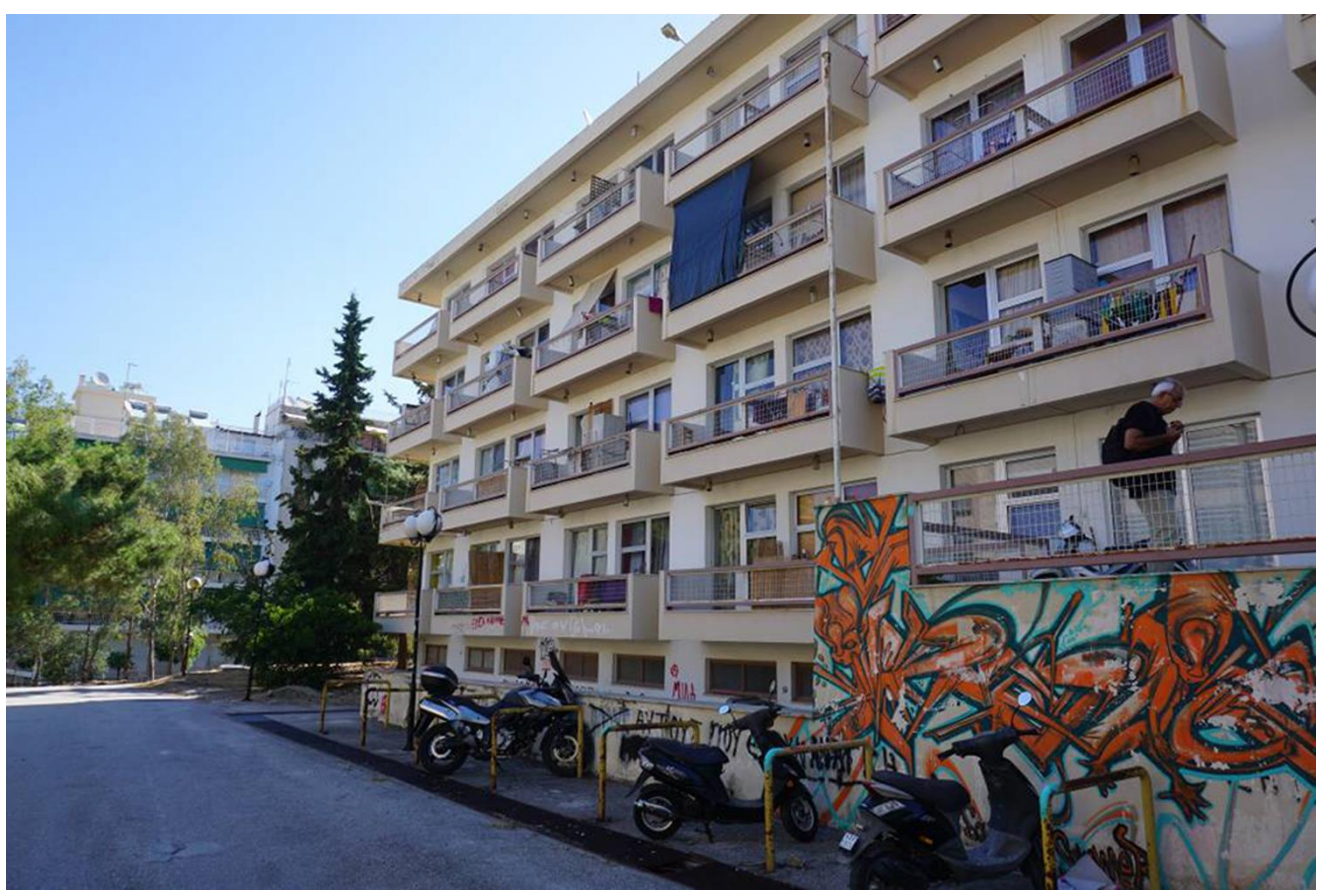

Figure 3. Student residence façade of the existing building. (@ 2018, Authors).

\subsection{Preliminary Digital Survey}

BIM models can be considered an archive of information generated and managed throughout the life cycle of the building and characterized by a high quantity and quality of information. Their ability to enable easy access to information further facilitates the better design, construction, operation and maintenance of a certain building [1,3,5,9,15].

The key factor for the implementation of a structured BIM process is, therefore, the correctness of the information contained in the models. To solve problems deriving from inaccurate, obsolete or missing information, especially in relation to interventions on the existing heritage, reality acquisition technologies, such as 3D laser scanning, is widely adopted $[2,3,5,27]$.

The digitalization of geometries (and materials) constitutes the first step of a broader informative description and identification of the constituent elements of an existing or 
planned building [10]. Compared to traditional detection tools, 3D laser scanning is extremely advantageous due to its high measurement accuracy and speed, and thus allowed the technical team to create a highly accurate three-dimensional digital representation in a very short time. The multiple scans necessary for the representation of a complex building must be brought together in a composite point cloud, and thus the laser scan data obtained provide a representation of the geometries (but also structured lighting and photogrammetry) which are then imported into a modeling environment to create later BIM models $[2,3,10,15,50]$.

The process of translating laser scan data into digital components in a BIM environment is known as "Scan-to-BIM" [3,10,50-52].

Although automated techniques are being implemented, the common practice in the sector is still to import the laser scanning data into BIM environments and then manually create all the elements in reference to the imported data. The actual creation of BIM models relies on the establishment of topological relationships between the various building components that are still extremely difficult to automate [3,52].

This is the procedure adopted in the early stages of Pro-GET-onE; in the specific case of the Athens case study, a knowledge base that aimed at the highest degree of confidence in the existing structure proved to be of fundamental importance (Figure 4).

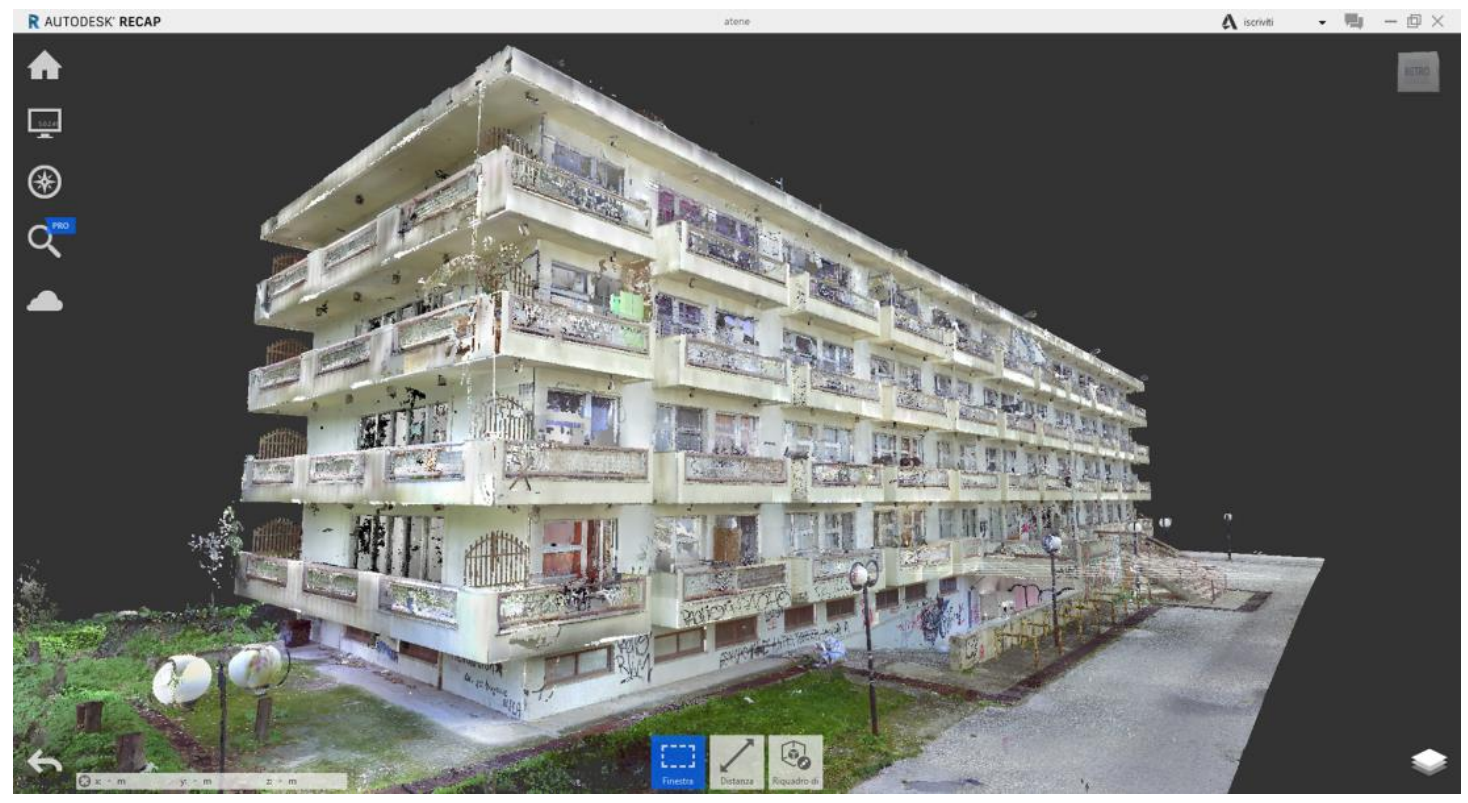

Figure 4. Composite point cloud from laser-scanner survey of the student residence, Athens (survey carried out from 4th to 11th February 2018 by Davide Prati and Anastasia Fotopoulou, University of Bologna) (C 2018, D. Prati).

Considering the goal of efficiency and prefabrication of the intervention, it was essential to minimize errors and tolerances on plug-and-play elements. One of the main goals was, in fact, to optimize the design toward a quick intervention and without wasting resources.

The numerous surveys were carried out using a Faro Cam2 Focus3D 120 laser scanner device, capable of covering a range up to $120 \mathrm{~m}$, with a linear distance error limited to $\pm 2 \mathrm{~mm}$ at $10 \mathrm{~m}$ and $25 \mathrm{~m}$, considered a reflectivity of $90 \%$ and $10 \%$.

For the survey of the exteriors, it was decided to perform scans at $1 / 4$ resolution, $4 \times$ quality (setting time about 8:50 min) for a total of about 110 scans made with color acquisition of 44 million points per scan.

For the interiors, on the other hand, a $1 / 8$ resolution was adopted with $3 \times$ quality (taking time about 2:30 $\mathrm{min}$ ) for a total of about 220 scans divided for the various floors. These scans were performed using only the reflectance threshold (they are black and white, 
but the brightness of the detected object defined the grayscale). Each of these scans contain approximately 11 million points. The alignment process followed was targetless and was mainly based on the "Cloud to Cloud" algorithm of the Faro Scene software. The final point cloud that was used as the basis for the development of the BIM model of the building includes about 2.5 billion total points, and the average density is around $2 \mathrm{~mm} \mathrm{[3].}$

This approach proved to be very effective and precise compared to conventional survey methods, greatly facilitating the acquisition and digitalization of the geometry of the building and providing a solid information base on the "as-is" status of the building. The biggest technical problems were found in the alignment of the scans outdoors where the vegetation complicated the alignment procedures. However, it should be also noted that rooms are not always easy to survey, as many elements are hidden by ceilings or occluded in the walls. For example, extensive work had to be done in collaboration with a structural survey in order to achieve a good level of detailing for the structural components of the building (pillars, beams and slabs) which proved to be very different from the original design drawings.

\subsection{Coordination and Collaboration at Different Levels}

The design phase of this project, although promoted by the University of Bologna, was a team effort involving many figures, starting with several project partners, various designers, consultants and companies involved in manufacturing and construction. The realization of this project therefore required a high degree of coordination and collaboration. This required multiple levels of communication. At a first level, communication was needed between the parties involved regarding quality, intentions, context and procedures. This was achieved mainly through the exchange of materials on the Common Data Environment (CDE) and frequent meetings. At another level, different representation tools and the need for a critical data exchange between the different tools were foreseen, as members of the project team used different digital tools to support specific activities within their competence.

In order to allow easier collaboration on the virtual model of the building, it was therefore decided to implement multiple federated BIM models on Autodesk Revit relating to the various disciplines and work phases. As a first step, starting from the laser scanner data, two models of the existing building were created: one architectural and one structural. Subsequently, the design phase of the intervention was started, and three further models were created: a structural model of the exoskeleton, an architectural model of the external skin, and a model of the systems. Different figures, with the help and collaboration of consultants, developed these models, each in their own field of expertise. A great facilitation was that all models were linked to each other, allowing the various figures to immediately obtain information on the other models and to easily check how their own work related to that of the others. In addition, another enormous advantage of this procedure was the possibility of promptly verifying the results of certain design choices across disciplines. For example, the definition of the exoskeleton had several iterations due to the different approaches to the design of the structural elements, but it was easy to check the impact of individual choices on the other disciplines and, thus, to speed up the time considerably.

The authors also point out that the traditional practice is to consider architectural drawings as nothing more than "design intentions" and that all the specific and coordination aspects of the components must be addressed in a further series of drawings, coordination documents and shop drawings for the production of elements. The multidisciplinary approach based on the shared models adopted in this project, on the other hand, made it possible to evaluate, step by step, all the design choices (including those of a technical nature) in order to achieve a high degree of optimization and an acceptable compromise between the conceptual design and built work. 


\subsection{BIM Phasing and Design Options}

A variety of applications with data overlay requirements are available to support the various areas of the design and construction phases. For this purpose, not only were design platforms, such as ArchiCad, Revit or Digital Project, considered, but also construction model platforms, such as Tekla, Structureworks, etc. In all these platforms, both a wide range of data and rules for object integrity management are incorporated. Moreover, interoperability between platforms and between platform and analysis tools is a fundamental prerequisite for projects developed using a BIM-based methodology. In order to benefit from the wider range of tools available, Autodesk Revit was chosen.

In fact, Revit is a MS Windows-based BIM platform, and it is currently among the best known and most widely used BIM software. Within the Revit platform, there are different flavors of products meant to assist professional designers involved in different disciplines: Revit Architecture, Revit Structure and Revit MEP. Revit is, therefore, a very powerful platform, especially because of the large number of applications supported and the wide range of Autodesk software that integrate very well with each other.

In line with the results obtained from the point cloud, the digital model of the existing building was generated (Figure 5a). This allowed the evaluation of all processed information, such as material characteristics, deformation of building elements, pathologies, construction or reconstruction phases, and metadata of any other type of elements. Through the function of project phasing, that tracks the phase in which all views or elements are created or demolished (Figure $5 \mathrm{~b}$ ), it was possible to integrate the information in the Revit model. The phase filtered then permitted to control the flow of building model information into views and schedules, and hence, to create phase-specific project documentation.

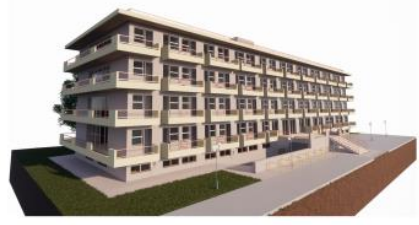

(a)

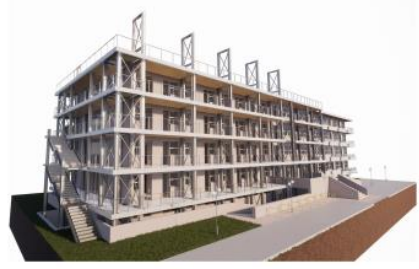

(d)

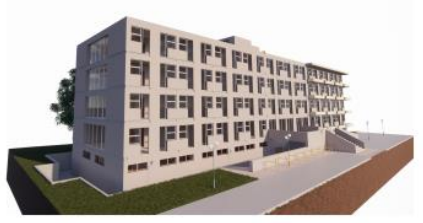

(b)

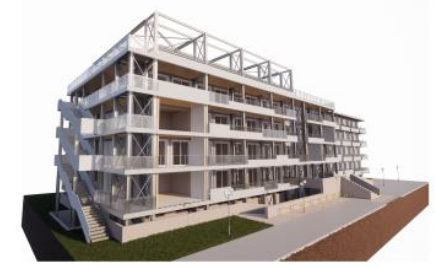

(e)

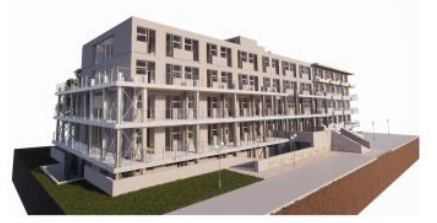

(c)

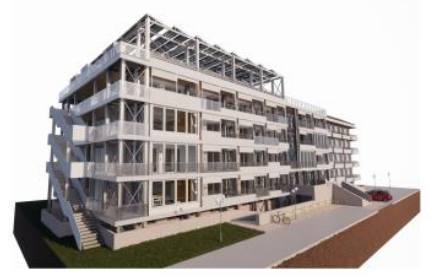

(f)

Figure 5. Views of the models at different BIM phases: (a) existing building; (b) demolition of the balconies and excavation for the pillars' foundations; (c) assembly of the first set of steel portal frames and floors; (d) assembly of the second set of steel portal frames and floors; (e) placing of exterior insulation, replacement of window frames and assembly of perforated sheet metal railings; (f) construction of frontal and side walls, installation of photovoltaic plant (@ 2019, M. Iannantuono).

In accordance with the project targets, the structure of the GET system will be applied externally (Figure 5c,d) without compromising the residents' habits, as it does not require any special operations to be carried out inside the buildings, while optimizing the installation using prefabricated elements.

The different variants of the GET system, therefore, consist of pre-assembled modular elements, for example floor, walls, railing, finishes and solar protection, which allow the various façade additions to be combined according to the needs of the users in a "user oriented" scheme (Figure 5e).

The objective is to have maximum versatility and interchangeability of the various modular elements, including the plant engineering elements, that will constitute these 
spaces. The GET system also allows an increase in the living units' size, resulting in a building market value increase.

The assembly and mounting features will be implemented to obtain the maximum versatility of the construction system, which can be unconventionally defined as "Plug\&Play".

In addition, the optimal energy standards will be sought, considering the construction cost thresholds. Thanks to this technology, it is possible to create composite technological packages that guarantee performance stratification, allowing the creation of ad hoc envelopes (Figure $5 \mathrm{f}$ ).

Moreover, "ready-for-use" is also guaranteed by adequate systems design which, thanks to careful planning, reduces the waste and downtime associated with traditional technology. In wet buildings, in fact, because of the need to create tracks in the walls for the systems, construction times are considerably longer, while in dry technology, the meticulous study eliminates the need to demolish parts of the building to insert the systems.

The architectural design, in addition to the integrated HVAC systems, and the installation of photovoltaic panels on the roof, guarantee an increase in the architectural value, a considerable reduction in terms of consumption and, therefore, in costs, the improvement of indoor comfort and air quality, as well as the optimization of resources.

\subsection{Energy Analysis}

In this section, the use of information modeling in energy and lighting analyses during different design phases is outlined, based on the building SMART standards [31] and the uBIM guides [53].

An energy analysis conducted on the basis of BIM models represents an important tool that guides designers for achieving a sustainable design project in a more systematic, transparent and efficient way than the one offered by the traditional methods.

The comprehensive use of energy analyses covers all stages of a project's design phase, from conception, construction and commissioning to verification that the executed installations meet the property requirements and the design criteria.

The success of the energy objectives and sustainability conditions is determined by the architectural, structural and system solutions. Therefore, it is crucial that designers cooperate from the pre-planning phases, in order to construct a coherent and optimal solution.

However, the major advantage of using BIM is that it supports the exchange of accurate data for calculations.

The use of BIM in energy analysis software has been possible for quite some time. However, there have been major faults in the definition of the required information for energy analyses and especially in the quality of the graphical interfaces of the BIM software used by designers.

To approach interoperability, the most important initial data used in the energy analyses are the ones from the BIM architectural model. The requirements of such an information model in terms of energy analyses can be presented in a simplified form, but this does not always guarantee successful data transfer. Therefore, when using this model, it may still be necessary to explore complementary solutions.

For the case study, an IFC file was exported from the Revit architectural model to generate the vertical and horizontal construction elements as well as the openings. Each room and the thermal zones were modeled to differentiate the internal space from the external and thus create a relationship between the object space and the envelope.

Upon the selection of the data, one should consider that maintaining the total height of the floor while not limiting it to the lower ceiling area, and modeling the spaces that comprise several floors, are key elements in ensuring safe exportation to the energy analyses software.

During the export, BIM software should be able to assign its categories to IFC classes using a mapping table. In fact, in the case of Revit, this is possible since the table is stored as a text file ( $\left.{ }^{*} \mathrm{txt}\right)$ and can be customized directly in Revit or in a text editor (Figure 6). 


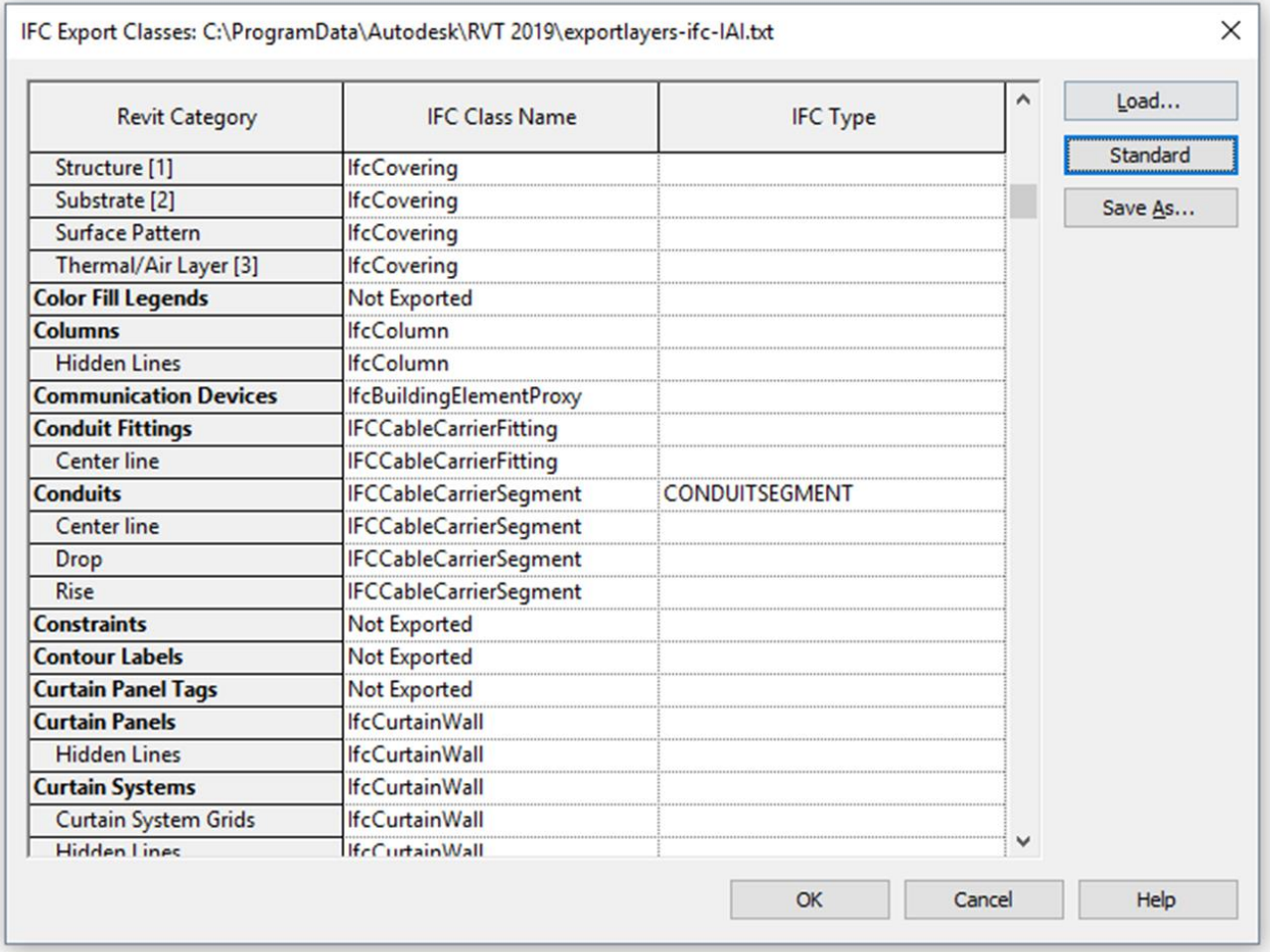

Figure 6. Revit IFC export classes table. (ㄷ 2019, M. Iannantuono).

According to the schematic table reported above, the first column, Revit Category, is non-editable and automatically lists all categories and subcategories available in the Revit project [54].

In particular, the IFC Class Name column contains the IFC class to which the category or subcategory should be assigned. Since the IFC schema is strictly modular and the proprietary Revit database collects objects following different criteria, a specific translation table had to be developed in order to guarantee proper data exchange among the different tools interacting with the model.

As, usually, only a subset of all IFC schema data is needed during the exchange for specific purposes, some portions of the whole dataset were exported to fulfil the design needs from time to time; this activity is commonly referred to as Model View Definition (MVD) [55]. Many of the IFC files were extracted following the consolidated IFC $2 \times 3$ Coordination view 2.0 in Revit, with small editing (Figure 7).

Normally, the most important decisions regarding the habitability, adaptability and energy efficiency of the buildings are made during the preliminary design or project phase. This is where size, shape, and layout of the spaces are determined and, indeed, are critical for the structural decisions and the quality level of the interior conditions.

The virtual management of energy performance and its requirements during conceptual design is possible in different ways using information modeling. The energy performance verification of a building that should be within sufficient ranges at the preliminary stages is an important marker to consider.

Significant initial data used in the energy analysis, as already mentioned, are the BIM architectural model in the different phases of the project (conceptual design, schematic design, design development, building permit phase, etc.).

During the Conceptual Design phase, the analyses of energy performance are used to study alternative solutions based on thermophysical calculations. These analyses, which are based on reference values or project benchmarks, can be used to test whether energy consumption targets are realistic and achievable. In this phase, the calculations 
of the thermal loads were carried out using specific applications integrated in the open information exchange that allow the import of geometric BIM models using the IFC format.

Calculations were based on the Radiant Time Series Method (RTSM) proposed and recommended by the American Society of Heating, Refrigeration and Air-conditioning Engineers (ASHRAE) [56] for calculating the cooling heat loads and the calculation procedures for heating loads, both detailed in the Load Calculation Applications Manual of 2014 [57].

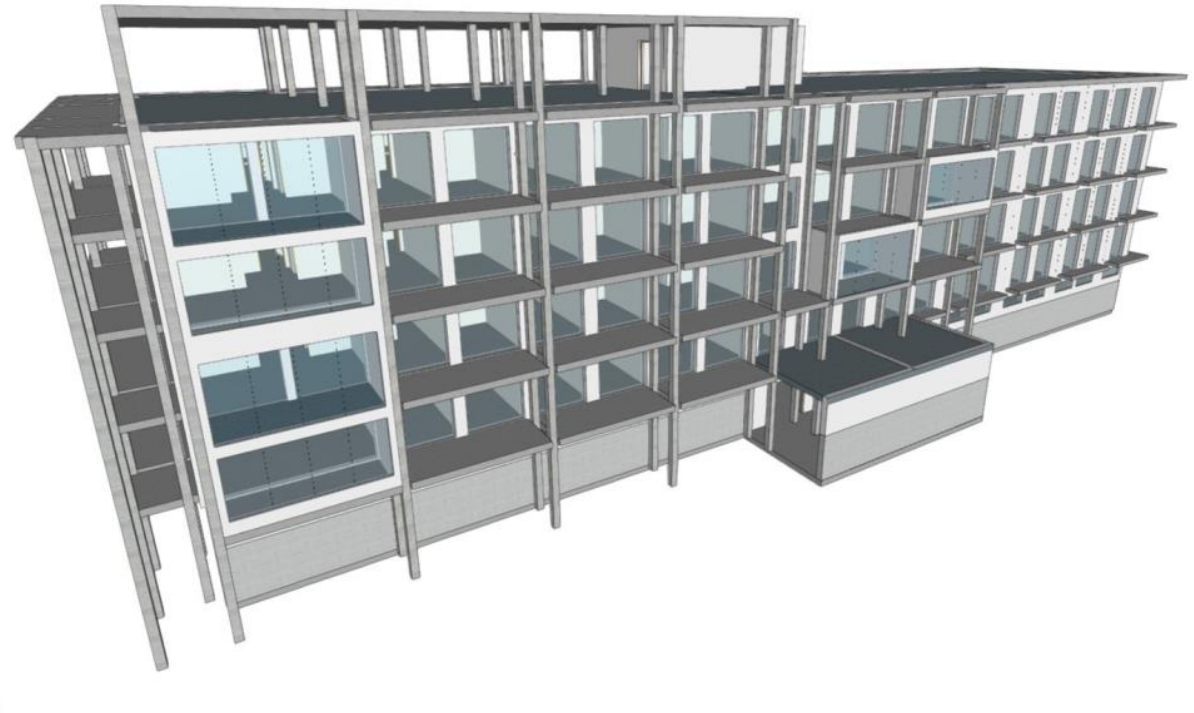

Figure 7. IFC model exported from Revit. (C 2019, M. Iannantuono).

From the IFC model, it was possible to calculate the cooling heat load for $24 \mathrm{~h}$ of the monthly day average and its maximum, as well as the heating load for all rooms and zones and its maximum.

In addition, real-time graphs of the results allowed a clear and immediate visualization of the impact of any design changes for the sizing of the MEP systems in later stages of the project (Figure 8).

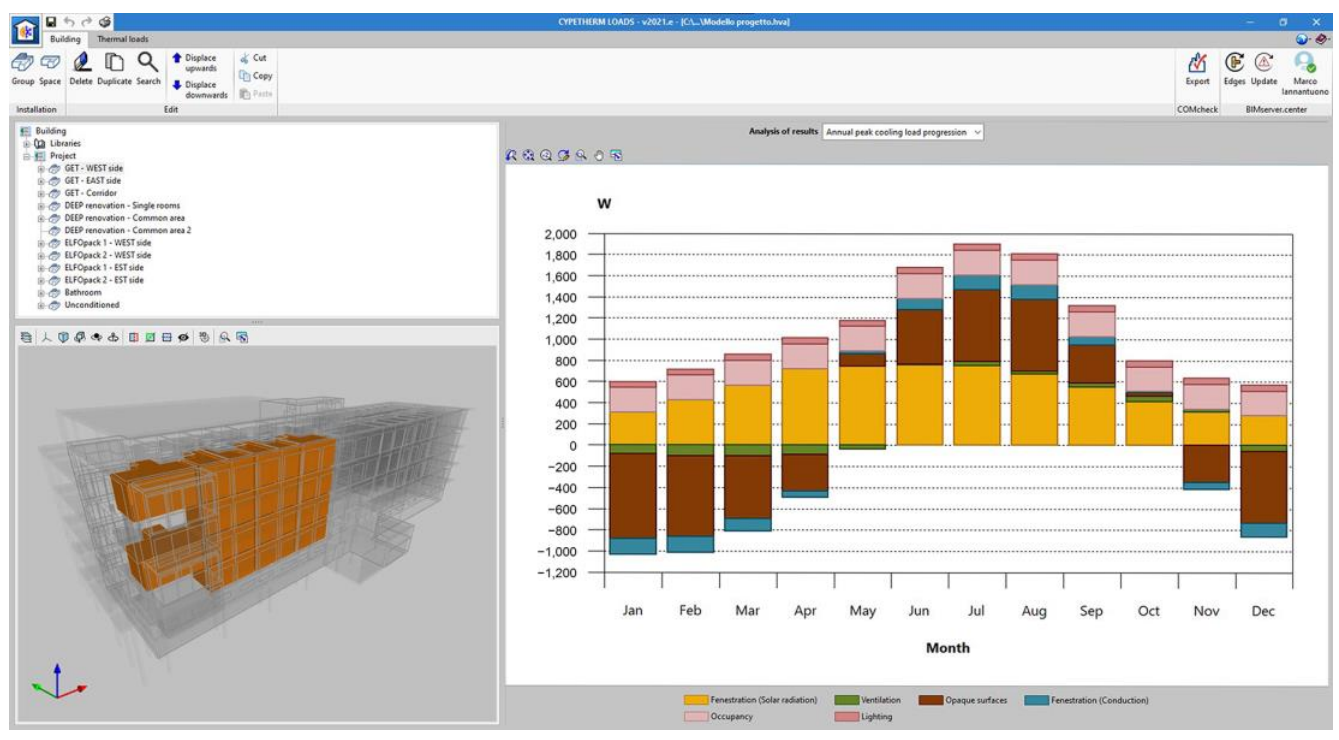

Figure 8. An example of real-time graph of annual development of maximum cooling load (c) 2019, M. Iannantuono). 
Various hypotheses for grouping rooms into thermal zones have been identified and selected to analyze them by using the software's graphic and parametric results, which is the most convenient in terms of optimizing resources and achieving comfortable room conditions. As a result of the calculation and the continuous verification of the thermal loads, according to the various design solutions, the size of the external and the internal units could be optimized.

The objective of the energy analysis in the design development phase is to simulate its effect in terms of energy consumption and conditions. To achieve a valid simulation, the air-conditioning requirements have been calculated separately for all thermal zones, thus taking into account any differences, e.g., orientation and heat load. In addition to detailed architectural modeling data, structural data are also required, as well as the types of openings used, including both doors and windows.

Energy consumption and interior condition simulations made in the design development phase serve to compare different façades, their solar protection and the technical solutions of the systems. Energy simulation of the building was performed by using EnergyPlus ${ }^{\mathrm{TM}}$, a renowned and powerful calculation engine for energy simulations in the dynamic regime, also integrated with IFC in the information exchange. The software can integrate climate parameter files in EnergyPlus Weather Format (EPW), available at the official EnergyPlus ${ }^{\mathrm{TM}}$ web page [58].

As far as materials are concerned, it was possible to take advantage of parameters from the library of UNI 10351 and EN 10456 standards, and other building materials based on international standards. The objectives are the calculation of energy requirements and primary energy consumption of the arranged air conditioning systems, determining the results for each system and energy source. For example, Figure $9 \mathrm{~b}$ shows the energy balance of the building for each month, accounting for energy lost or gained by thermal transmission through heavy and light elements, energy exchanged by ventilation and infiltration, internal heat inputs due to occupancy, lighting and internal equipment, and lastly the inputs needed for heating and cooling. On the other hand, Figure $9 \mathrm{c}$ shows the instantaneous useful power during the annual heating and cooling simulation.
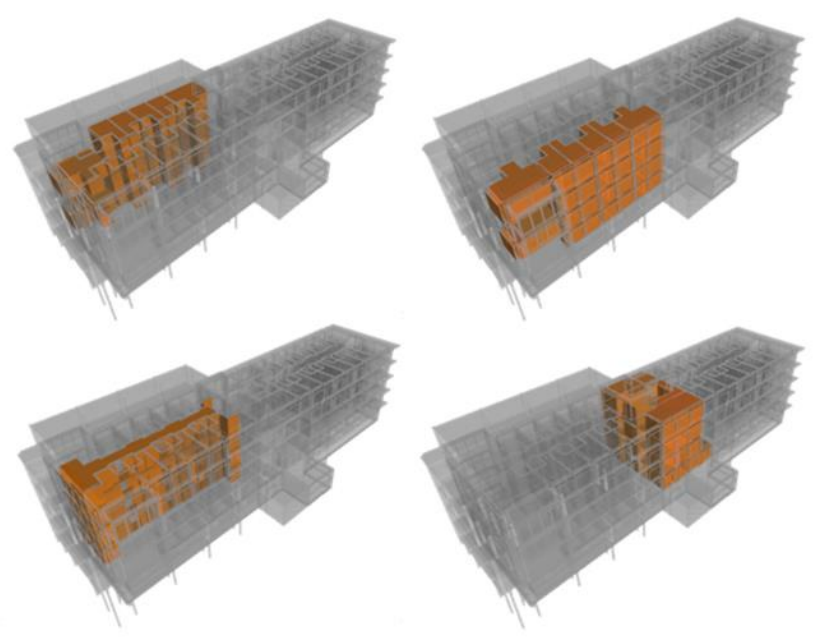

(a)

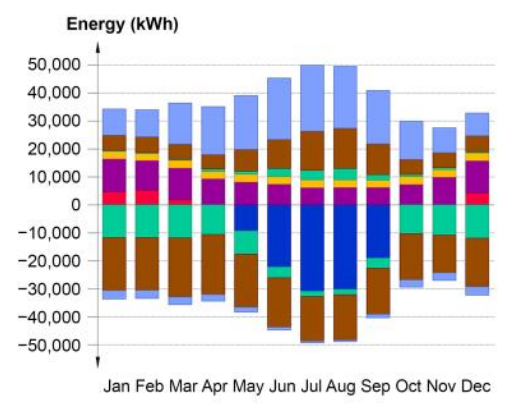

(b)

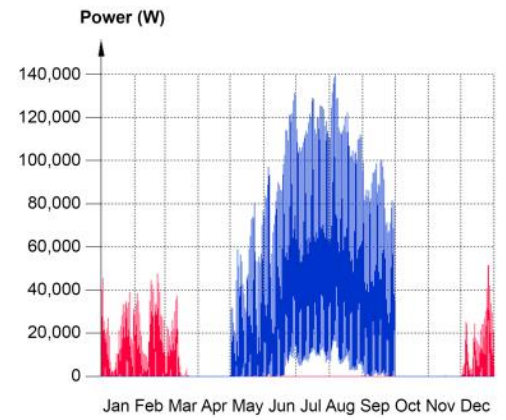

(c)

Figure 9. (a) Examples of thermal zones; (b) graph of energy balance of the building for each month (kWh); (c) graph of instantaneous useful power for each month (W) ( 2019, M. Iannantuono). 
In this phase, energy analysis software can additionally be used in MEP design, providing a simulation of the indoor conditions and sizing of air-conditioning requirements according to the comfort needs of the spaces. The simulation results of the comfort conditions can be exported back to BIM through IFC format and, thus, create the initial data needed for the design of the HVAC system (Figure 10).

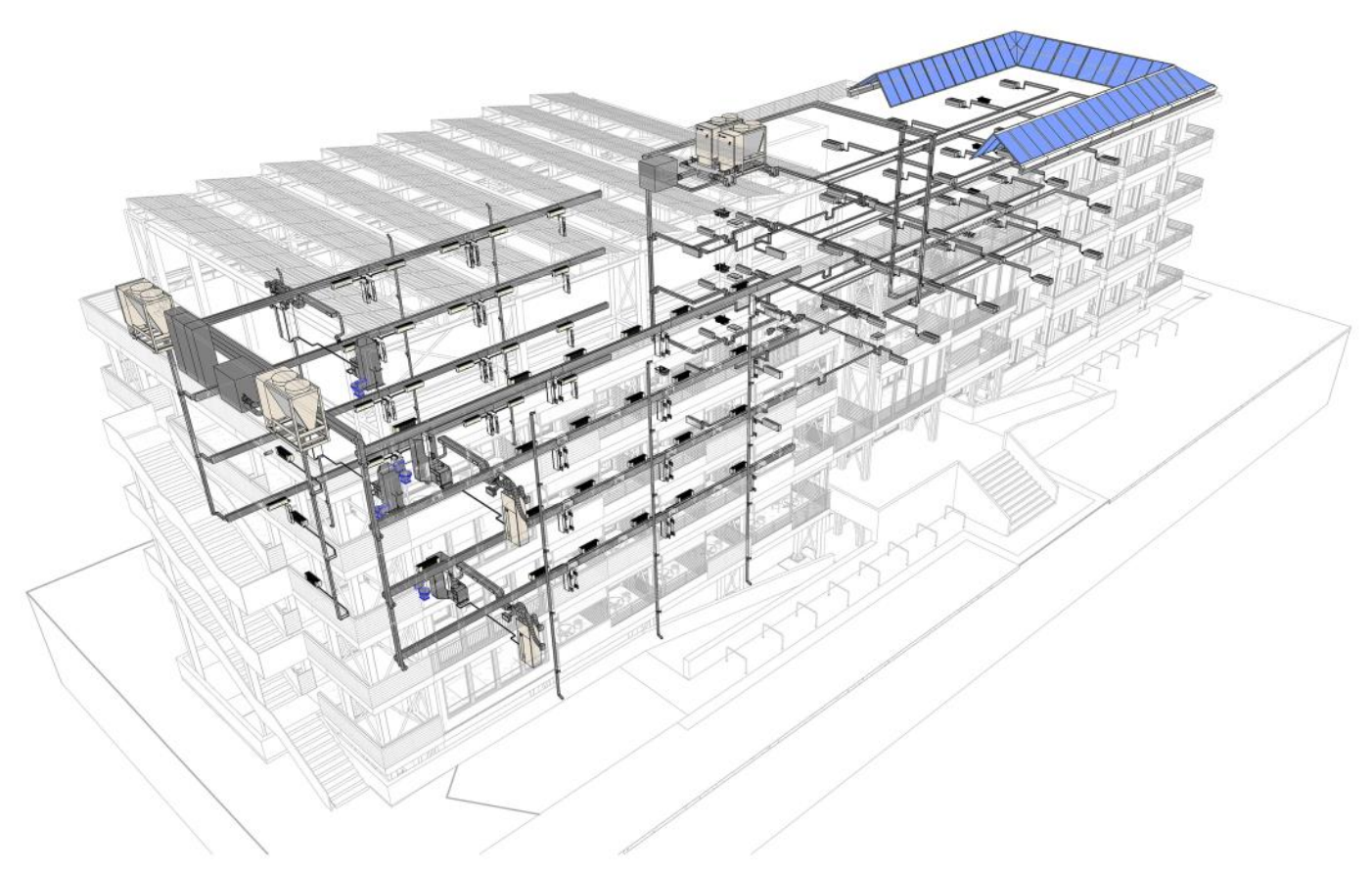

Figure 10. View of the MEP model linked to the architectural and structural models (C) 2019, M. Iannantuono).

\subsection{Lighting Analysis and Visualization}

The combination of the MEP model with the architectural and structural BIM model allows to estimate how the MEP devices (ventilation terminal equipment, lighting fixtures, etc.) fit into the architecture of the building. Based on the available BIM models, and the integration of lighting devices into the model through IFC, the lighting calculation was also carried out to calculate and represent numerically the brightness provided by the lighting devices in the room/space and the glare index (reflection) on the various surfaces. The results were the calculation of the lighting level of the installation measured at work plane level, as well as the calculation of the energy efficiency value of the installation. Due to the complexity of the model, the calculation could be carried out in a sample space or in all the necessary spaces (Figures 11 and 12).

The luminaires used in the calculation have been imported from the library available in the application, but it is possible to define the manufacturer's data manually or to import model information files in ELUMDAT format (standard format in Europe for photometric data—extension "ldt") or IES format (standard format in North America for photometric data-extension "ies").

The "automatic distribution" command has been used to arrange the luminaires. This allows the luminaires to be spaced out automatically, thus achieving a greater degree of uniformity of illuminance on the work surface and saving on the cost of the installation.

Once the calculation has been carried out, it is possible to display on the screen the results of illuminance of the zones involved in the calculation, using iso-values, iso-lines or numerical values (Figure 13). 


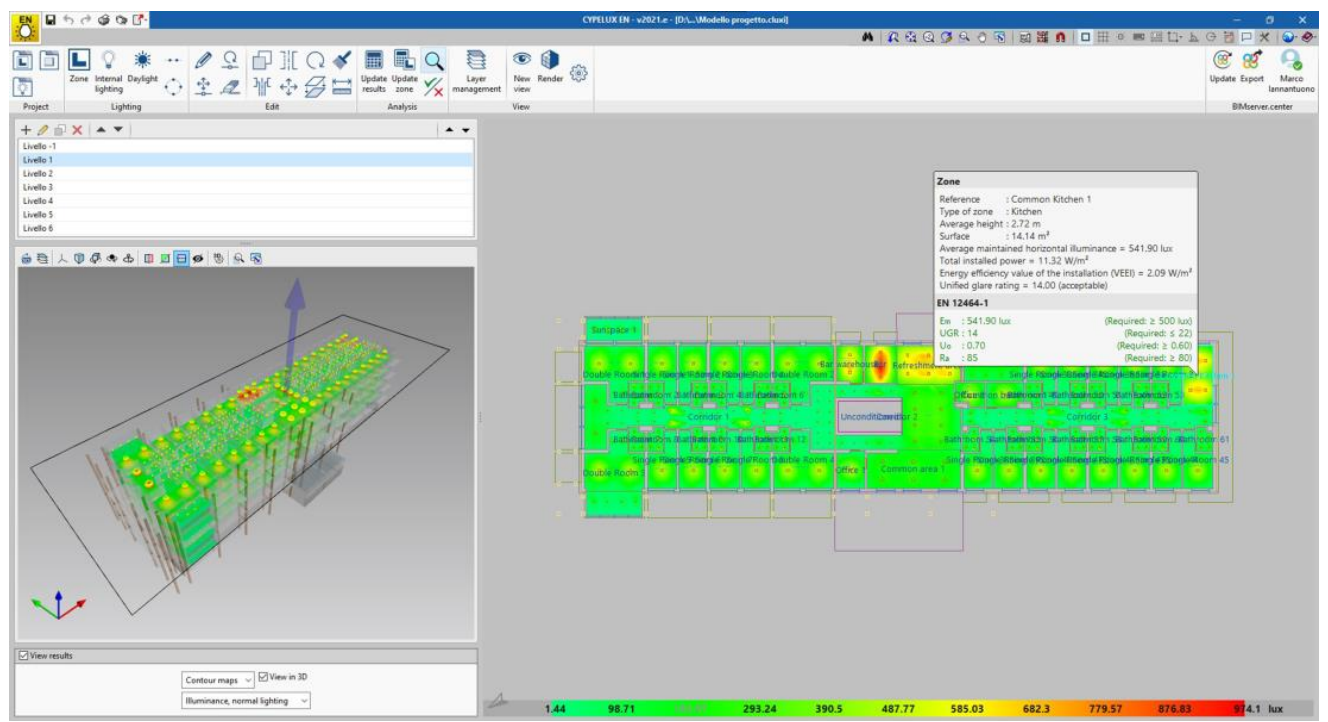

Figure 11. Result of illuminance for the ground floor (iso-values) (@ 2019, M. Iannantuono).

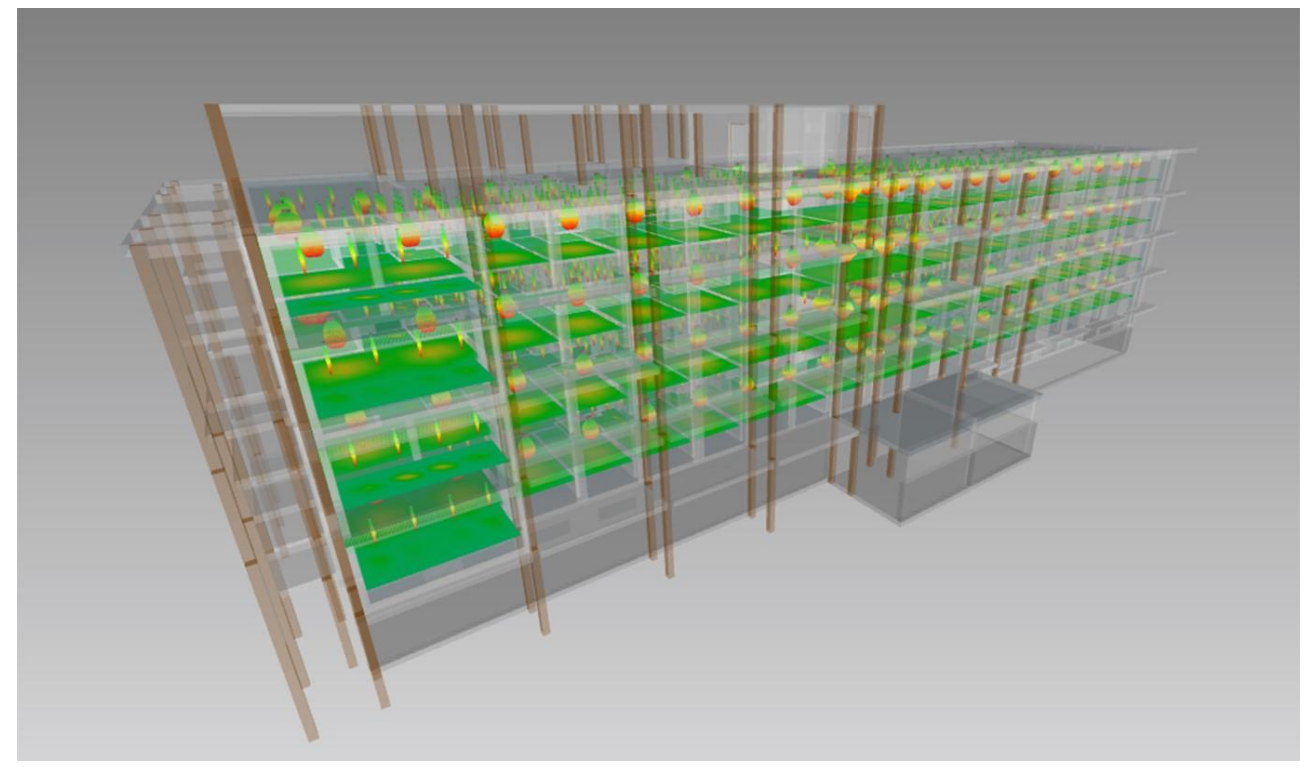

Figure 12. IFC model updated with lighting devices and visualization of calculation surfaces (@ 2019, M. Iannantuono).

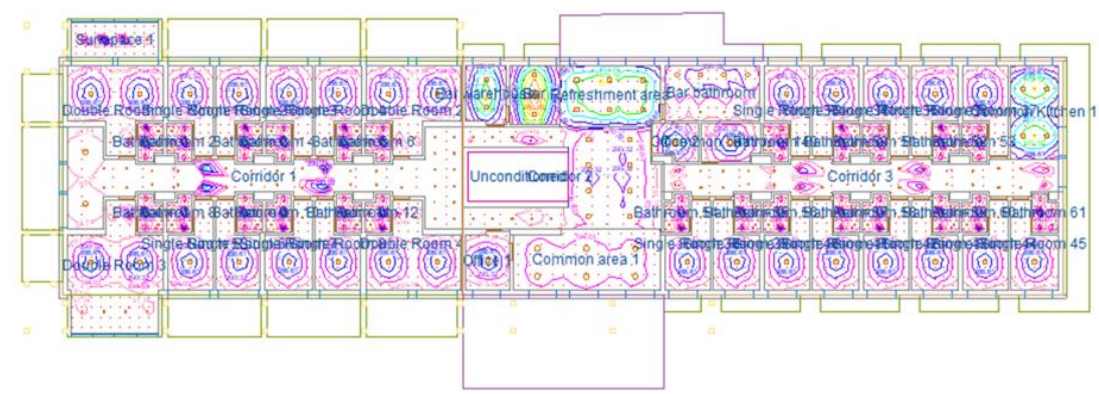

Figure 13. Result of illuminance for the ground floor (iso-lines) (@ 2019, M. Iannantuono). 
The lighting calculation requires considerably less effort than the lighting simulation, but the results obtained are less illustrative. The lighting visualization was used to illustrate the effects of the lighting produced by the selected devices on the interiors and the illumination of the space (Figure 14a). In addition, a rough study of the effects of daylight and glare (reflection) were carried out (Figure 14b).

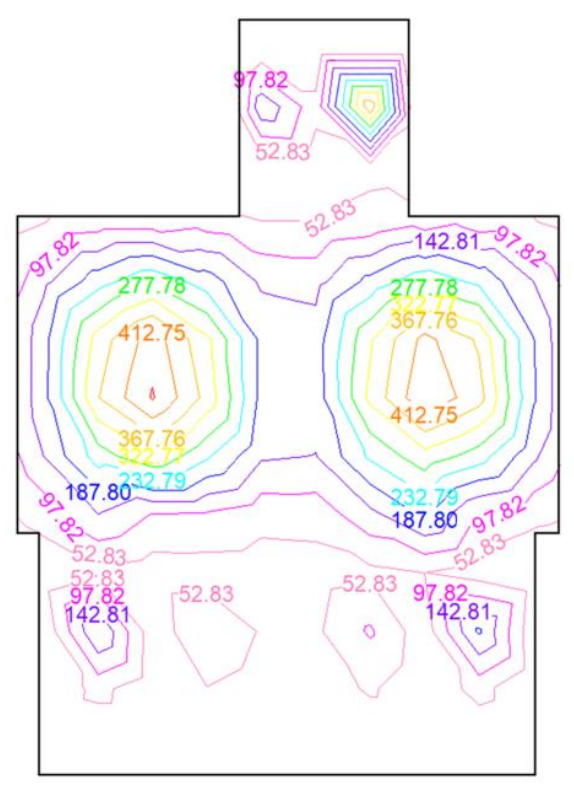

(a)

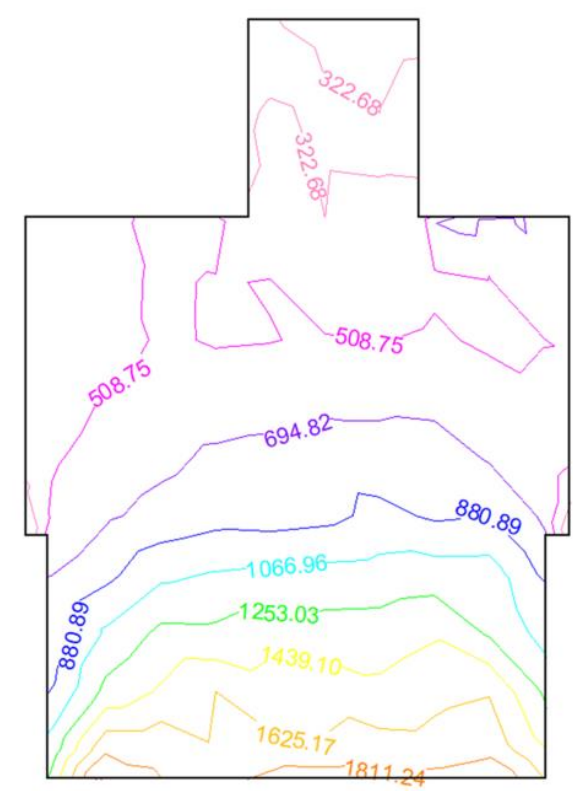

(b)

Figure 14. Result of illuminance for the extra-room (iso-lines). (a) Artificial lighting calculation; (b) natural lighting calculation (ㄷ 2019, M. Iannantuono).

The simulation software used in the lighting simulation must be able to calculate the real illumination with different light points and to calculate the reflection of light on different material surfaces. The architectural BIM model, together with the electrical design, can be used for the lighting simulation. When the intention is to examine the final appearance or lighting conditions in a workspace, for example, the architectural model should include the furniture in the space. To achieve a lighting simulation as close to reality as possible, it is often necessary to modify or redo the 3D model of the space or building to correspond to the requirements of the simulation programs.

Lighting simulation is usually done by combining the spaces with the lighting of the facades (Figure 15).

Another extremely important factor to consider for the design or renovation of lowenergy buildings is incident solar radiation, which has a more or less marked influence on the performance of buildings, depending on whether it is a favorable or undesirable component. This aspect is particularly relevant when considering the re-shape of the buildings' facades, and even more when adding new extensions on the existing buildings. As a matter of fact, solar radiation, in its different forms of direct radiation from the sun, indirect radiation, diffused through the atmosphere and air particles, and reflected radiation provide different energy contributions to buildings. Thus, assessing the climatic context of a building during the design phase, paying attention to reflective surfaces or fixed obstacles in the surroundings, is extremely important.

The simulation can also be used to examine the behavior of daylight in different spaces. The resulting photorealistic visualizations resemble photographic images and represent real conditions quite close to reality, visualizing the different levels of illumination on 
each of the rooms surfaces, for different hours of the day on different days of the year (Figure 16).

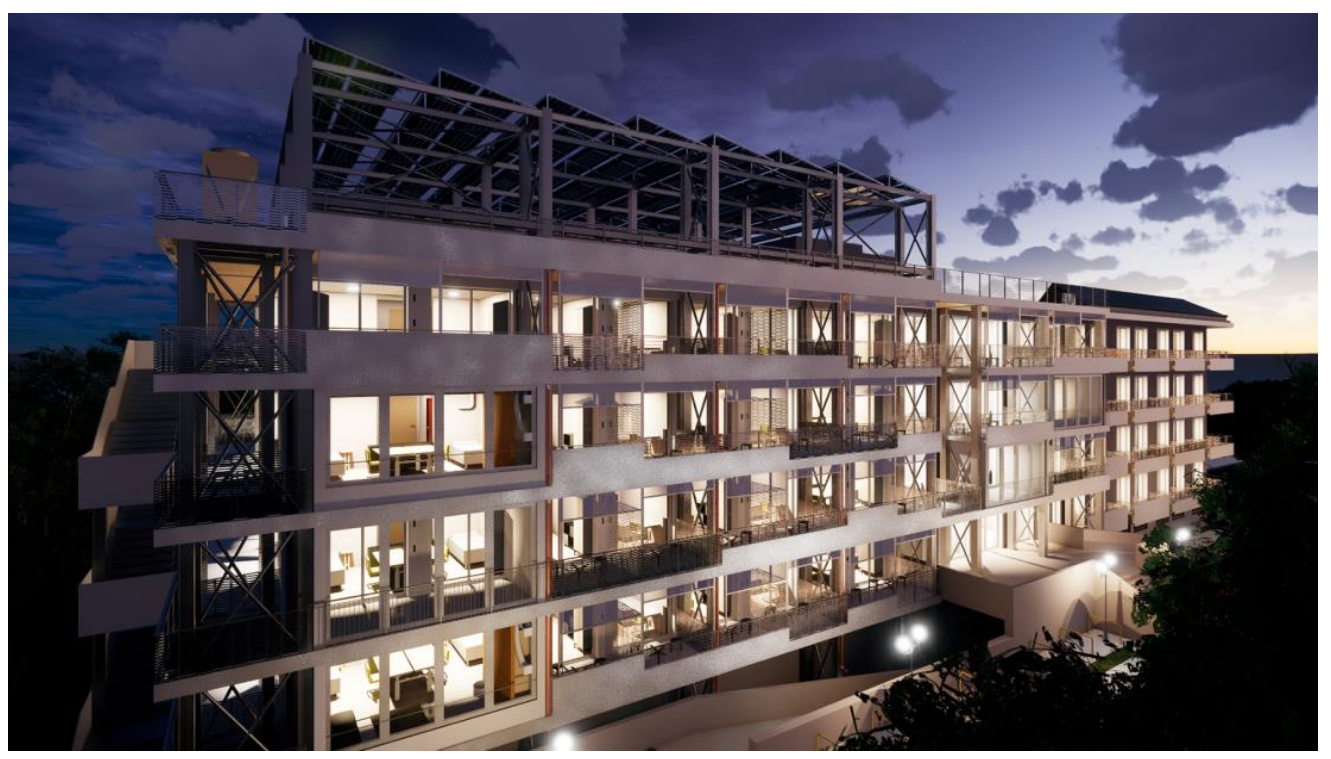

Figure 15. Lighting simulation of the façade in real-time rendering (ㄷ 2019, M. Iannantuono).

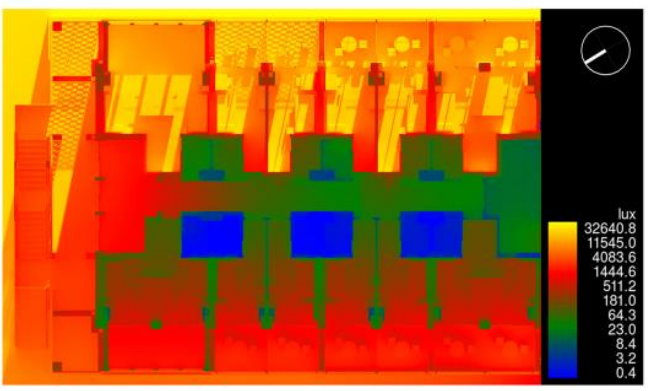

(a)

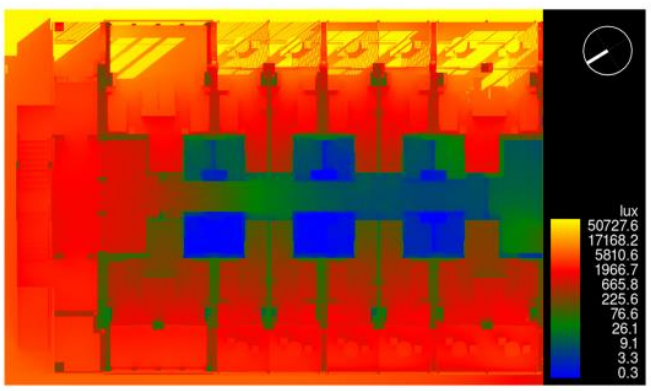

(c)

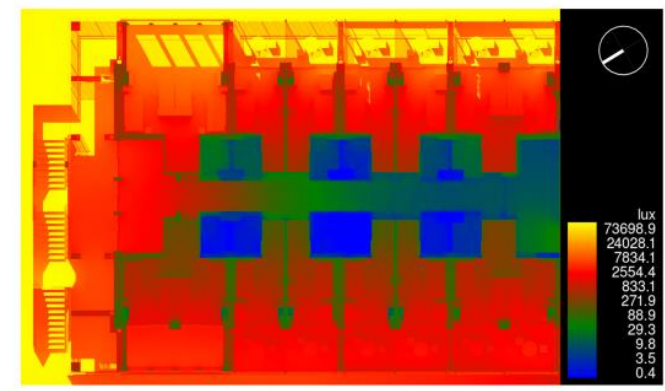

(b)

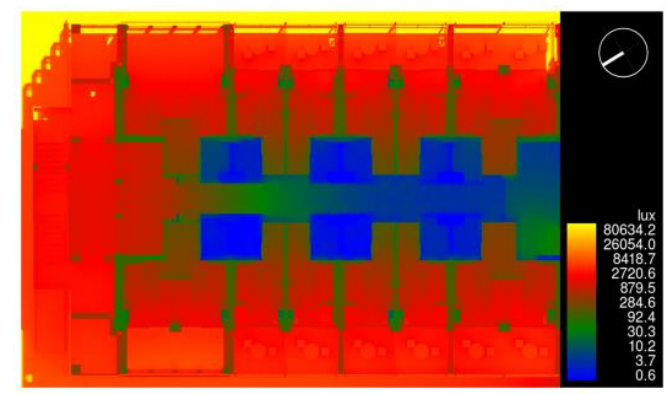

(d)

Figure 16. Illuminance rendering in Revit. (a) 21st December 9:00 a.m. (b) 21st June 9:00 a.m. (c) 21st December 12:00 p.m. (d) 21st June 12:00 p.m. (C 2019, M. Iannantuono).

These results allow the optimal design of solar control devices, such as shading, envelope finishes, window size and window solutions. We can say that the sun can be considered a design tool, with considerable influence on the shape, orientation, openings, stratigraphy and materials chosen, as well as the shading. The simulation of light- 
ing with the model can also be used to create animations, when necessary, using the real-time rendering.

Real-time rendering and virtual reality also enable visual exploration directly in the modeling tool, in a full immersion experience, so it is possible to focus on the creation, design, and implementation of all elements of the buildings and have a real-time consistency with changes for visual control of spaces and interferences [59].

In retrofit scenarios, image visualization techniques make the placement and appearance of building construction systems and MEP equipment easy for the user to observe and understand while highlighting the technical details (Figure 17).

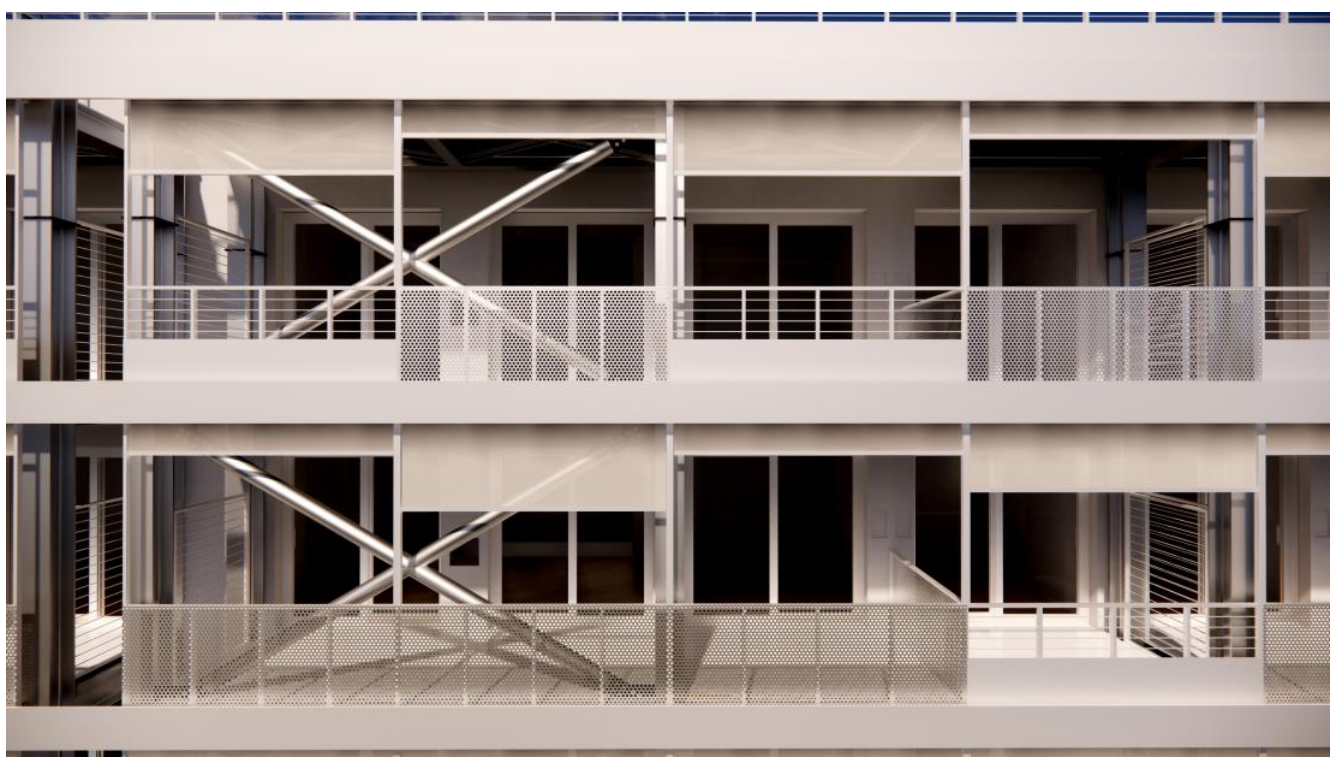

Figure 17. Technical details in real-time rendering ( 2021, M. Iannantuono).

\section{Discussion}

The main purpose of this research is to contribute to demonstrating the potential of the BIM process as a powerful method for the sustainable re-design of the built environment, and to describe and analyze steps to be adopted in practical applications. The focus is therefore on the process and, for this reason, the quantitative and numerical results (of each simulation) are not reported, as they are not coherent with the objective of this paper.

Throughout the project, all source data have been processed according to the same design phase and any conflicts have been communicated, verified and resolved thanks to the effectiveness and efficiency of the collaborative processes assisted by BIM technologies. Digital models, in fact, were extensively shared among professionals involved in the design activity, becoming, in this way, a formal language by which issues and discrepancies were discussed and reworked in a coordinated workflow. Moreover, all necessary source data were checked before each simulation, and the results have been documented and shared among all the figures involved in a Common Data Environment (CDE) to ensure integrity and to avoid clashes between the different disciplines.

The CDE was at first difficult to set up, due to the specific need of a shared policy in data management. Following a schematic data structure, as reported in Section 4.3, contents were organized in different database areas in order to split work-in-progress activities from consolidated ones. Following the CDE general recommendations in [22], the data repository was later improved to host documents and reports from professionals and institutions involved in the project. These new features implied a general management of the whole data structure, which introduces the need for a specific role targeted to the task: the CDE manager, who is in charge of setting up the repository and coordinating flows in and out of it. 
Nevertheless, sometimes BIM models had to be exported in different file formats in order to share critical information with partners, professionals or companies with limited knowledge of BIM applications. In some cases, the results of the analyses and simulations were presented in dwg format and a 2D drawing, or in the form of reports and scheme diagrams (Figure 1).

While the extended use of IFC proved to be effective in data sharing, it could not offer all the classes that were considered necessary in the project management, particularly when referring to the visualization stage, as indicated in Section 4.6. This was a paramount step in presenting the design outcomes to clients, and to evaluate properly the results of the lighting analysis according to the materials features and design intents, for example.

Therefore, further studies are necessary to enhance the adaptability of this format, which is essential for the generation of BIM interoperable flows that can be adopted within the proposed processes. The BIM models that provided the basis for the analysis were also used for the visualization of the results, as the forementioned simulations can be visualized within the same software interface, as with the case of solar studies and lighting simulations. Similarly, 3D visualization was also used for clash detection simulations of all building elements, using real-time rendering.

Based on the analyses carried out, and thanks to the creation of a BIM-abacus, as a tool for the selection of different and user-centric options of façade solutions and space configurations, the different intervention scenarios could be displayed preliminarily, thus supporting and guiding the design decisions. Once these design solutions were selected, they were further refined in a fluid design process that led to the optimal configuration in terms of environmental and construction quality. Moreover, the research presented in these pages can also be considered as a starting point for the development of further research activities, such as the integration of Life Cycle Assessment (LCA) based on BIM elements. LCA can be used to assess energy consumption, consumption of "raw materials" (building materials), construction emissions and the life cycle of the building elements. In this way, the environmental characteristics of all design solutions and the different retrofit configurations can be analyzed according to an integrated and holistic approach.

Even though each design activity has to be developed according to criteria and needs that are often different for each project, the process tested in this research program was adaptable to the various occurrences, from the reports production stage to the practical design procedures. As a general outcome, BIM proved to be effective when all the figures involved are mature enough to apply its principles in a proper way, considering the data coherency in digital models, how to validate it and how to extract necessary graphic or alphanumeric information from the model database. The BIM chain works when all its parts are linked: this is a further aspect to be considered when planning the BIM adoption in a design team and the homogeneous maturity level is the first mandatory step to guarantee successful replicability in other projects, not necessarily similar in terms of the building's extension.

Planning regular meetings and preparing internal training for the research partners to reach a common level of maturity were operational steps which led to a novel application of the BIM criteria, since actors came from different countries with different codes and regulations, all dedicated to a project in a specific location with needs that were often diverse from the ones that they were used to considering.

\section{Conclusions}

The case study introduced in this contribution showed the potential offered by modern BIM technologies in fostering and guiding the sustainable re-design of the existing building stock.

Due to the early adoption of information modeling since the initial phases of the design, it has been possible to analyze the management and organizational characteristics within the design process of an energy and user-oriented retrofit. 
Thanks to the extensive use of BIM models, it was easy to make regular reviews with the different practitioners involved in the design and construction processes. Improved quality of information, visualization tools, cost estimation and energy analysis have undoubtedly led to an informed decision-making process from the early design stage, with the aim to reduce inefficiencies during the construction stage.

However, coherence between increasingly large groups of technical reports and drawings, also when adopting computer-aided drafting tools and document control systems, is extremely challenging because of the mutual interactions between the complexity of modern buildings and the increasing targets of energy, environmental and construction quality required in the contemporary sustainable design process.

Moreover, during the phases of the executive design process, collaborative work is often carried out by multiple specialists and collaborators. Their coordinated activities should ideally provide each specialist with the appropriate design information he/she needs, the desired use he/she searches for and the corresponding environment, to perform reviews and to give feedback on consultancy or modification.

To fully benefit from the advantages of a methodology that promotes interoperability and shared processes and reduces errors by detecting clashes, such as BIM, many further steps are necessary: on the one side, the share workloads among practitioners who do not use the same tools or design standards is required; in parallel, further improvements in the same interoperability among different software and tools should be researched and accomplished.

While possible limitations, as reported also in the discussion section, are due mainly to the nonuniform application of BIM techniques by the partners or the difficulties arising from the adoption of software frameworks that still do not flawlessly share data formats, the use of BIM along the project was successful enough to consider it as a valid methodology to test, coordinate and validate the participated design choices. Future developments will consider further dimensions in BIM adoption, such as the feasibility of model integration during the building stage, or the later facility management, with the whole dataset updated and checked to collect correct information for the operational stage.

Author Contributions: Conceptualization, A.F. (Annarita Ferrante), C.M. and A.F. (Anastasia Fotopoulou); methodology, A.F. (Annarita Ferrante), M.I., V.G.; software, M.I., V.G.; validation, S.G.; formal analysis, design A.F. (Anastasia Fotopoulou), C.M.; investigation, M.I., V.G.; data curation, M.I.; writingoriginal draft preparation, M.I., V.G.; writing-review and editing, A.F. (Annarita Ferrante), C.M., A.F. (Anastasia Fotopoulou) and S.G.; visualization, M.I., V.G.; supervision, C.M. and A.F. (Annarita Ferrante); funding acquisition, A.F. (Annarita Ferrante) ("Pro-GET-onE" G.A. No 723747). All authors have read and agreed to the published version of the manuscript.

Funding: The research project received funding from the European Union's Horizon 2020 Innovation action under grant agreement No 723747.

Institutional Review Board Statement: Not applicable.

Informed Consent Statement: Not applicable.

Data Availability Statement: Not applicable.

Acknowledgments: The analysis presented in Chapter 4 was developed by Marco Iannantuono in the framework of his master's thesis entitled "Progettazione Integrata per l'ottimizzazione Energetica ed ambientale mediante BIM. Un caso di studio del progetto europeo Pro-GET-OnE" (Alma Mater Studiorum-University of Bologna; supervisor: Semprini, G.; co-supervisor: Garagnani, S.; García Quesada, R.; Cantelli, D; Ferrante, A.). The first concept visualizations were developed by Alessandra Cinti in her master's thesis entitled "Riqualificazione architettonica ed energetica. Un caso di studio ad Atente" (Alma Mater Studiorum-University of Bologna; supervisor: Ferrante, A.).

Conflicts of Interest: The authors declare that there are no conflict of interest regarding the publication of this paper. 


\section{References}

1. Eastman, C.; Teicholz, P.; Sacks, R.; Liston, K. BIM Handbook: A Guide to Building Information Modeling for Owners, Managers, Designers. In Engineers and Contractors, 2nd ed.; Wiley: Hoboken, NJ, USA, 2011; ISBN 978-0-470-54137-1.

2. Weisberg, D.E. The Engineering Design Revolution: The People, Companies and Computer Systems That Changed Forever the Practice of Engineering. Available online: https:/ / www.cadhistory.net/ (accessed on 12 January 2021).

3. Ferrante, A.; Garagnani, S.; Fotopoulou, A.; Giannakopoulos, V. D.6.3 BIM Implementation for Energy, Seismic and User-Oriented Design; Project Deliverable: Bologna, Italy, 2020; Available online: https:/ /www.progetone.eu/download (accessed on 18 March 2021).

4. EUBIM Taskgroup. Handbook for the Introduction of Building Information Modelling by the European Public Sector-Strategic Action for Construction Sector Performance: Driving Value, Innovation and Growth; EUBIM Taskgroup: Brussels, Belgium, 2018.

5. Acca Software, S.p.A. Guida al BIM 2 La Rivoluzione Digitale DELL'EDILIZIA. Available online: https://www.acca.it/ebookguida-al-bim (accessed on 12 January 2021).

6. Chemise, S.; Renou, J. Revit per il BIM. Guida alla Progettazione Architettonica e Strutturale; Apogeo: Milan, Italy, 2018; ISBN 978-88-503-3461-2.

7. Giannakopoulos, V.; Garagnani, S.; Fotopoulou, A.; Ferrante, A. Approccio Computazionale alla Progettazione: Digitalizzazione dei processi informativi per l'Architettura sostenibile. In Proceedings of the Colloqui.AT.e 2020—New Horizons for Sustainable Architecture, Catania, Italy, 17-20 June 2020; pp. 901-918.

8. Cinti Luciani, S.; Garagnani, S.; Mingucci, R. BIM Tools and Design Intent. Limitations and Opportunities. In Practical BIM 2012-Management, Implementation, Coordination and Evaluation, Los Angeles, USA; Kensek, K., Peng, J., Eds.; University of Southern California: Los Angeles, CA, USA, 2012; pp. 19-27.

9. Azhar, S. Building Information Modeling (BIM): Trends, Benefits, Risks, and Challenges for the AEC Industry. Leadersh. Manag. Eng. 2011, 11, 241-252. [CrossRef]

10. Garagnani, S. Semantic Representation of Accurate Surveys for the Cultural Heritage: BIM Applied to the Existing Domain. In Handbook of Research on Emerging Digital Tools for Architectural Surveying, Modeling, and Representation; IGI Global: Hershey, PA, USA, 2015; pp. 292-310.

11. United Nations The 17 Goals. Available online: https://sdgs.un.org/goals (accessed on 18 March 2021).

12. World Economic Forum. Shaping the Future of Construction: A Breakthrough in Mindset and Technology; Industry Agenda: Geneva, Switzerland, 2016.

13. Charef, R.; Emmitt, S.; Alaka, H.; Fouchal, F. Building Information Modelling Adoption in the European Union: An Overview. J. Build. Eng. 2019, 25, 100777. [CrossRef]

14. Panteli, C.; Polycarpou, K.; Morsink-Georgalli, F.Z.; Stasiuliene, L.; Pupeikis, D.; Jurelionis, A.; Fokaides, P.A. Overview of BIM Integration into the Construction Sector in European Member States and European Union Acquis. IOP Conf. Ser. Earth Environ. Sci. 2020, 410, 012073. [CrossRef]

15. Gerbert, P.; Castagnino, S.; Rothballer, C.; Renz, A.; Filitz, R. Digital in Engineering and Construction: The Transformative Power of Building Information Modeling; The Boston Consulting Group: Boston, MA, USA, 2016.

16. European Commission. Joint Research Centre. Building Information Modelling (BIM) Standardization; Publications Office: Luxembourg, 2017; ISBN 978-92-79-77206-1.

17. DigiPLACE Project. Available online: https:/ /www.digiplaceproject.eu/ (accessed on 18 March 2021).

18. SPHERE Project. Available online: http://sphere-project.eu/ (accessed on 18 March 2021).

19. DIGITALEUROPE Project. Available online: https://www.digitaleurope.org/projects/ (accessed on 18 March 2021).

20. P2Endure Project. Available online: https://www.p2endure-project.eu/en (accessed on 15 April 2021).

21. E-SAFE Project. Available online: http:/ / esafe-buildings.eu/en/ (accessed on 15 April 2021).

22. ISO 19650-1:2018 Organization and Digitization of Information about Buildings and Civil Engineering Works, Including Building Information Modelling (BIM)—Information Management Using Building Information Modelling_Part 1: Concepts and Principles. Available online: https://www.iso.org/cms/render/live/en/sites/isoorg/contents/data/standard/06/80/68078.html (accessed on 18 March 2021).

23. Garagnani, S. Il BIM della conoscenza condivisa: La modellazione informativa digitale come evoluzione della disciplina del Disegno. In BIM Views Esperienze e Scenari; Papa, M.P., D’Agostino, P., Eds.; CUA: Salerno, Italy, 2019; pp. 41-49.

24. Mansfeld, I.; Zuppiger, A.D. 10 Motivi per cui il Formato IFC è la Chiave per il Successo della Progettazione BIM; ALLPLAN GmbH: Munich, Germany, 2017.

25. Garagnani, S. Il BIM dell'esistente. Verso la digitalizzazione evoluta del patrimonio costruito. In BIM-Oggi—Italia; Rossi, A., Ed.; LibreriaUniversitaria: Limena, Italy, 2019; pp. 47-71.

26. D'Oca, S.; Opt Veld, P.; Tisov, A. State of the Art of Deep Energy Renovation; Project Deliverable: Bologna, Italy, 2017; Available online: https: / / www.progetone.eu/download (accessed on 18 March 2021).

27. Mansfeld, I.; Muck, W. Produttività Aumentata del 30-35\% Grazie alla Progettazione 3D; ALLPLAN GmbH: Munich, Germany, 2018.

28. Ferrante, A.; Mochi, G.; Predari, G.; Badini, L.; Fotopoulou, A.; Gulli, R.; Semprini, G. A European Project for Safer and Energy Efficient Buildings: Pro-GET-OnE (Proactive Synergy of InteGrated Efficient Technologies on Buildings' Envelopes). Sustainability 2018, 10, 812. [CrossRef] 
29. Fotopoulou, A.; Ferrante, A.; Badini, L.; Predari, G.; Mochi, G.; Sempreini, G.; Gulli, R.; Assimakopoulos, M.; Papadaki, D. An Integrated System for Façade Additions Combining Safe, Energy Efficient and Userorientated Solutions. Tema Technol. Eng. Mater. Archit. 2019, 5, 72-81. [CrossRef]

30. Iannantuono, M. Progettazione Integrata per l'ottimizzazione Energetica ed Ambientale Mediante BIM. Un Caso di Studio del Progetto Europeo Pro-GET-OnE. Master's Thesis, University of Bologna, Bologna, Italy, 2019.

31. BuildingSMART Standards \& Technologies. Available online: https://technical.buildingsmart.org/standards/ (accessed on 18 March 2021).

32. Redmond, A.; Hore, A.; Alshawi, M.; West, R. Exploring How Information Exchanges Can Be Enhanced through Cloud BIM. Autom. Constr. 2012, 24, 175-183. [CrossRef]

33. Al Hattab, M. The Dynamic Evolution of Synergies between BIM and Sustainability: A Text Mining and Network Theory Approach. J. Build. Eng. 2021, 37, 102159. [CrossRef]

34. Bastos Porsani, G.; del Valle de Lersundi, K.; Sánchez-Ostiz Gutiérrez, A.; Fernández Bandera, C. Interoperability between Building Information Modelling (BIM) and Building Energy Model (BEM). Appl. Sci. 2021, 11, 2167. [CrossRef]

35. De Gaetani, C.I.; Mert, M.; Migliaccio, F. Interoperability Analyses of BIM Platforms for Construction Management. Appl. Sci. 2020, 10, 4437. [CrossRef]

36. The American Institute of Architects-AIA. Integrated Project Delivery: A Guide. Version 1; AIA: Washington, DC, USA, 2007.

37. Wang, Y.; Thangasamy, V.K.; Hou, Z.; Tiong, R.L.K.; Zhang, L. Collaborative Relationship Discovery in BIM Project Delivery: A Social Network Analysis Approach. Autom. Constr. 2020, 114, 103147. [CrossRef]

38. Jin, J.; Hwang, K.-E.; Kim, I. A Study on the Constructivism Learning Method for BIM/IPD Collaboration Education. Appl. Sci. 2020, 10, 5169. [CrossRef]

39. Piroozfar, P.; Farr, E.R.P.; Zadeh, A.H.M.; Timoteo Inacio, S.; Kilgallon, S.; Jin, R. Facilitating Building Information Modelling (BIM) Using Integrated Project Delivery (IPD): A UK Perspective. J. Build. Eng. 2019, 26, 100907. [CrossRef]

40. Jones, B. Integrated Project Delivery (IPD) for Maximizing Design and Construction Considerations Regarding Sustainability. Procedia Eng. 2014, 95, 528-538. [CrossRef]

41. Assimakopoulos, M.-N.; Masi, R.F.D.; Papadaki, D.; Ruggiero, S.; Vanoli, G.P. Energy Audit and Performance Optimization of a Residential University Building in Heating Dominated Climates of Italian Backcountry. Tema Technol. Eng. Mater. Archit. 2019, 4, 19-33. [CrossRef]

42. Ferrante, A.; Fotopoulou, A.; Semprini, G.; Cantelli, D.; Ruggiero, S.; Karalis, M.; Efthymiou, C.; Papadaki, D.; Assimakopoulos, M.-N. IEQ and Energy Improvement of Existing Buildings by Prefabricated Facade Additions: The Case of a Student House in Athens. IOP Conf. Ser. Mater. Sci. Eng. 2019, 609, 042047. [CrossRef]

43. Barmparesos, N.; Papadaki, D.; Karalis, M.; Fameliari, K.; Assimakopoulos, M.N. In Situ Measurements of Energy Consumption and Indoor Environmental Quality of a Pre-Retrofitted Student Dormitory in Athens. Energies 2019, 12, 2210. [CrossRef]

44. Industry Foundation Classes (IFC). Available online: https://technical.buildingsmart.org/standards/ifc/ (accessed on 18 March 2021).

45. ProGETonE. Solutions for More Comfortable, Efficient and Seismic-Safe Homes. Available online: https://www.progetone.eu/ (accessed on 18 March 2021).

46. Fotopoulou, A.; Badini, L.; Mochi, G.; Predari, G.; Roijakkers, R.; Cojocaru, R. Seismic Strengthening through External Exoskeleton. Tema Technol. Eng. Mater. Archit. 2018, 4, 34-51. [CrossRef]

47. Badini, L.; Stefano, C.A.D.; Custodi, A. Seismic Strengthening of Existing RC Structure through External 3D Exoskeleton. In Proceedings of the 20th Congress of IABSE, New York, NY, USA, 4-6 September 2019; pp. 1018-1024.

48. Ott, S.; Krechel, M. Construction Principles of Seismic and Energy Renovation Systems for Existing Buildings. Tema Technol. Eng. Mater. Archit. 2018, 4, 66-80. [CrossRef]

49. The Project Triangle. Available online: https://support.office.com/en-us/article/the-project-triangle-8c892e06-d761-4d40-8e1f$17 \mathrm{~b} 33 \mathrm{fdcf} 810$ (accessed on 22 January 2020).

50. Bosché, F.; Ahmed, M.; Turkan, Y.; Haas, C.T.; Haas, R. The Value of Integrating Scan-to-BIM and Scan-vs-BIM Techniques for Construction Monitoring Using Laser Scanning and BIM: The Case of Cylindrical MEP Components. Autom. Constr. 2015, 49, 201-213. [CrossRef]

51. Laing, R.; Leon, M.; Isaacs, J.; Georgiev, D. Scan to BIM: The Development of a Clear Workflow for the Incorporation of Point Clouds within a BIM Environment; WIT Transactions on The Built Environment: Bristol, UK, 2015; pp. 279-289.

52. Garagnani, S. Building Information Modeling and Real World Knowledge. A Methodological Approach to Accurate Semantic Documentation for the Built Environment. In Proceedings of the 2013 Digital Heritage International Congress (DigitalHeritage), IEEE, Marseille, France, 28 October-1 November 2013; pp. 489-496.

53. Guías uBIM. Available online: http:/ / www.buildingsmart.es/bim/guías-ubim/ (accessed on 18 March 2021).

54. Revit IFC Manual. Available online: https://damassets.autodesk.net/content/dam/autodesk/draftr/2528/180213_IFC_ Handbuch.pdf (accessed on 18 March 2021).

55. Pinheiro, S.V.; Wimmer, R.; Maile, T.; O’Donnell, J.; Al, E. Model View Definition for Advanced Building Energy Performance Simulation. In Proceedings of the CESBP/BauSIM 2016 Conference, Dresden/Berlin, Germany, 14-16 September 2016.

56. ASHRAE. Available online: https:/ / www.ashrae.org/ (accessed on 18 March 2021).

57. Spitler, J.D. Load Calculation Applications Manual, 2nd ed.; I-P Edition; ASHRAE: Atlanta, GA, USA, 2014; ISBN 978-1-936504-75-6.

58. EnergyPlus. Weather Data. Available online: https:/ / www.energyplus.net/weather (accessed on 18 March 2021).

59. Johansson, M.; Roupé, M.; Bosch-Sijtsema, P. Real-Time Visualization of Building Information Models (BIM). Autom. Constr. 2015, 54, 69-82. [CrossRef] 